\title{
Consumer resource integration and service innovation in social commerce: the role of social media influencers
}

\author{
Yao $\mathrm{Wu}^{1} \cdot$ Satish Nambisan ${ }^{2} \cdot$ Jinghua Xiao $^{1} \cdot \mathrm{Kang}_{\mathrm{Xie}}{ }^{1}$ (1)
}

Received: 7 April 2020 / Accepted: 31 December 2021 / Published online: 4 February 2022

(c) The Author(s) 2022

\begin{abstract}
Social media technologies have given rise to influencers who shape the purchasing behaviors of their followers (peer consumers), thus enabling consumer-initiated social commerce. However, few studies have explored how social media influencers, and more broadly, consumers, actively integrate resources to engage in service innovation in social commerce. This qualitative study (involving two firms and their influencers) examines the emerging roles of social media influencers and their resource integration behaviors in service innovation. Drawing on the service-dominant logic and the technology affordance theory, the study advances a framework that identifies the resource integration behaviors that underlie two primary roles of influencers—communicator and innovator—and explains how social media technology affordances facilitate these behaviors, and thereby, the ensuing innovation outcomes. By focusing on the technology-mediated processes of social media influencers' engagement in service innovation, we contribute to research and practice in consumer-led service innovation in the emerging digital world.
\end{abstract}

Keywords Service innovation · Social commerce $\cdot$ Social media influencers $\cdot$ Social media technologies $\cdot$ Technology affordances

\section{Introduction}

Social media technologies (SMTs) have opened novel opportunities for consumers to leverage their personal resources to engage with firms and become "influencers", thereby cocreating value and shaping the purchasing behaviors of their followers (peer consumers). Such social media influencersalso known as Instafamous, Key Opinion Leaders (KOL), and

Hope Schau served as Area Editor on this article.

Kang Xie

mnsxk@mail.sysu.edu.cn

Yao Wu

wuyao3@mail2.sysu.edu.cn

Satish Nambisan

spn24@case.edu

Jinghua Xiao

lnsxjh@mail.sysu.edu.cn

1 School of Business, Sun Yat-sen University, Xingang Road, Guangzhou 510275, China

2 The Weatherhead School of Management, Case Western Reserve University, Cleveland, OH, USA live streamer — combine their talent and likable personalities with their considerable social network following on various popular social media platforms (e.g., YouTube, TikTok, Twitch, Instagram, Twitter, and WeChat) to influence followers' perceptions of products and brands. The power of such influencers is evident in markets across the world (Backaler, 2018). For example, recently, China's top live streamer, Viya, sold \$30 million worth of products from New Zealand to her millions of Chinese followers in a matter of hours, which illustrates how such influencers have become an important medium to connect consumers with products and brands ${ }^{1}$.

The importance of these social media influencers is further enhanced due to the fragmentation of the social media environment and the ensuing creation of a large number of customer communities with vastly different consumption needs and profiles (Shan et al., 2019). ${ }^{2}$ In such contexts, social media influencers become indispensable for firms to

\footnotetext{
${ }^{1}$ Data source: https://www.nzherald.co.nz/business/chinas-top-livestreamer-viya-sells-30-million-worth-of-new-zealand-product-inhours/CFTEJ6PPIW5OOMCY6XD4ZJABEA/.

2 A survey on digital usage in China reports that there are at least 16 major social media sites in China that have a significant number of users in 2020 (https://www.statista.com/statistics/250546/leadingsocial-network-sites-in-china/).
} 
reach out to and understand the needs of the consumers in these different market segments and to create new brands to satisfy those needs. Social media influencers leverage interpersonal influence drawing on their social networks to facilitate transactional interactions and to create business value (Liang \& Turban, 2011; Stephen \& Toubia, 2010). Such consumer-initiated social commerce (CSC), with social media influencers playing a central role, has emerged as an important business model. Firms are acutely aware of this change and are spending an increasing proportion of their budgets on influencer marketing (Hughes et al., 2019). The popularity of social media influencers, and their cooperation with firms, stimulate resource combinations for value co-creation and service innovation in CSC.

Specifically, in the CSC context, social media influencers assume a lead role in marketing and service innovation by engaging in two-way interactions with firms and followers. They usually possess heterogeneous personal resources that are distinct from firm-owned resources (Harmeling et al., 2017) and generate para-social interactions (Knoll et al., 2015) making consumers more susceptible to their opinions and behaviors (De Veirman et al., 2017). Some of them gain fame by successfully branding themselves as experts or mavericks on social media platforms (Schouten et al., 2020). "Follower" consumers identify these influencers as like-minded peers (Daniel et al., 2018), trust them more than they trust traditional celebrities (e.g., actors, supermodels, and athletes; Schouten et al., 2020), and demonstrate greater appreciation for their product information sharing than for brand-promoted advertising (Lou et al., 2019).

Despite such evidence on the growing significance of social media influencers in service innovation and value creation, we have a limited understanding of how they actively integrate their resources to engage in and lead service innovation in CSC. Such resource integration has been the central focus of the Service-Dominant Logic (SDL) (Vargo \& Lusch, 2004, 2008); SDL views all economic entities who apply specialized competences (operant resources) as resource integrators (Vargo \& Lusch, 2004, 2008) and service innovation as the rebundling or integration of diverse resources that create novel beneficial resources (Lusch \& Nambisan, 2015). Such a perspective allows us to view social media influencers' resource integration-which entails combining specific operant and/or operand resources (Lusch et al., 2007) and which motivates and constitutes exchange with other individuals or organizations (Vargo \& Lusch, 2008) as consumer-led resource integration. While prior studies in SDL have examined such consumer-led resource integration, the focus has been only on consumers' efforts in creating value-in-use for themselves (Vargo \& Lusch, 2008); limited attention has been paid to consumer-led resource integration, involving firms, to create value-in-use for peer consumerswhich forms the focus of the current study.
Further, given that social media forms the vehicle for influencers' resource integration in CSC, the enabling role of SMTs also assumes equal importance (Kaplan \& Haenlein, 2010; Li et al., 2021). The technology affordance perspective (Markus \& Silver, 2008; Majchrzak \& Markus, 2012) has been advanced to understand how the properties of an object (e.g., technology features) relate to or intersect with the abilities and intentions of an actor (Cabiddu et al., 2014) and offer specific affordances or action possibilities (Volkoff \& Strong, 2013). From such a perspective, social media influencers' different goals lead to different action potentials of SMTs, as perceived by influencers, in the context of resource integration for service innovation. While prior studies have examined SMT affordances associated with intrafirm interactions, firm-led interactions with consumers, as well as community interactions in non-commercial settings (e.g. Lee et al., 2019; Cabiddu et al., 2014; Raja-Yusof et al., 2016), there has been limited focus on SMT affordances that assume salience in the context of consumer-led resource integration for service innovation.

Given the above research gaps, in this study, we seek to address three questions: (a) in what ways (roles) do social media influencers engage in consumer-led resource integration to create value-in-use for peer consumers? (b) what are the resource integration behaviors that underlie these roles that social media influencers play in service innovation? and (c) how do social media technologies facilitate or enable these resource integration behaviors?

We conduct a comparative case study of two Chinese firms and their social media influencers. Drawing upon multiple data sources, including semi-structured interviews, documents, and direct observations, we examine the differentiated roles and resource integration behaviors of the social media influencers at the two firms and examine how they lead to specific service innovation outcomes (individualized product promotion and individualized brand building). Based on the case study analysis and prior literature, we develop a conceptual framework of resource integration by social media influencers in service innovation.

In so doing, we seek to make three key contributions to future research on service innovation. First, most studies have focused on service innovations that are led by firms, wherein consumers play an important but largely passive and supportive role in resource integration (e.g. Edvardsson et al., 2012; Kristensson et al., 2004; Sudbury-Riley et al., 2020). We extend this work by identifying the ways by which consumers (here, influencers) initiate and assume lead roles in resource integration and service innovation. Second, by bringing a sharp focus on consumer-controlled resources and their resource integration behaviors, we show how customers enact their lead roles (as communicator and as innovator) in service innovation in the CSC context and create value-in-use for peer consumers. Third, by identifying SMT 
affordances related to consumer-led resource integration and service innovation, we complement and extend existing research that have so far focused only on SMT affordances in the context of intra-firm, firm-led, and non-commercial innovation contexts. And, in doing so, we also seek to offer a more nuanced understanding of technology-mediated microprocesses of consumer engagement in service innovation in the emerging digital world.

\section{Theoretical background}

\section{Service innovation under service-dominant logic}

Service innovation, as one of the three strategic priorities for service research (Ostrom et al., 2015), has been studied across disciplines (Patrício et al., 2018), and service-dominant logic has become a foundational theoretical perspective for this research (Barrett et al., 2015; Gustafsson et al., 2020; Skålén et al., 2015). Here, we adopt SDL as the theoretical lens for studying service innovation by considering its three core premises: a) service as fundamental to all economic exchange; b) service as based on the joint application of specialized competences (operant resources) by all economic entities who act as resource integrators; and c) value as co-created during interactions and subjectively determined by the consumers in context (Vargo \& Lusch, 2004, 2008). Building on these core premises, service innovation has been conceptualized as the integration (or rebundling) of diverse resources to generate novel resources that are valuable or beneficial to users in a given context (Lusch \& Nambisan, 2015). Two primary perspectives have been adopted by existing studies to explore service innovation: the firmdominant perspective and the service ecosystem perspective.

The firm-dominant perspective focuses on how service innovation is developed through organizational resource integration (Fang et al., 2011; Hughes et al., 2018; Ng et al., 2016; Skålén et al., 2015). An implicit assumption underpinning this perspective is that firms are service providers and the resource integration is carried out largely within the boundaries of the firm; while consumers may provide certain resources (e.g. needs information), they are passive participants in the resource integration process (e.g. Edvardsson et al., 2012; Kristensson et al., 2004; SudburyRiley et al., 2020). Such a perspective arose because most consumers are conventionally regarded as unable to innovate solely through resource integration, especially when they lack critical resources and/or technological support. In short, this perspective places limited attention on consumers who actively integrate resources for service innovation (Busser et al., 2019; Magnusson et al., 2003; Witell et al., 2016).

The ecosystem perspective, on the other hand, assumes that consumers play a more active role in service innovation
(Aal et al., 2016; Baron et al., 2017; Lusch \& Nambisan, 2015; Vargo et al., 2015). Service ecosystems are emergent actor-to-actor structures in which both firms and consumers play equally important roles in pursuing resource integration and value co-creation (Lusch \& Nambisan, 2015). However, while this stream of research emphasizes the role of consumers as an active agent in service innovation (Lusch \& Nambisan, 2015), it also tends to abstract all consumers by highlighting their common characteristics and, to varying degrees, ignoring the heterogeneity (e.g., different roles, resources, capabilities, and behaviors) among them that contributes to different service innovation outcomes. Further, there has been limited focus on understanding the specific resource integration behaviors that consumers exhibit to engage in service innovation.

Another rich stream of research has focused on consumers as 'lead users' and their role in product innovation (von Hippel, 1986, 2005). While studies in this area have examined how lead users identify emergent market needs and act upon them to develop new products and solutions, even becoming user entrepreneurs in some instances (Shah $\&$ Tripsas, 2007), they have not adopted the SDL perspective, and as such there has been no explicit focus on users' resource integration behaviors or processes.

Thus, more broadly, our understanding of the ways by which consumers assume lead roles, and actively integrate resources, to engage in service innovation is far from adequate in the extant literature, and SDL forms an appropriate theoretical perspective to address this critical research gap.

\section{Resources and roles of social media influencers}

Typically enabled by SMTs, social media influencers often assume a lead role in service innovation in the CSC context and are viewed as members of the consumer group with similar identity by their followers or peer consumers (Djafarova \& Rushworth, 2017; Erz \& Christensen, 2018). Indeed, as noted previously, it is their very identity as a consumer that affords them with the trust and influence among their followers (Schouten et al., 2020).

Social media influencers usually possess heterogeneous personal resources that are distinct from a firm's organizational resources. Harmeling et al. (2017) identified four types of such personal resources that customers typically possess and use in value creation: network assets that relates to customers' extent of interpersonal ties within their social network; persuasion capital which relates to their degree of trust, goodwill, and influence vis-à-vis other people in the community; knowledge stores which relates to their accumulation of knowledge about other customers, product/brand, and firm; and creativity which relates to their capability to deploy their knowledge and conceptualize or develop novel, useful ideas or solutions to problems. All of these 
Table 1. Firm-centered and consumer-led resource integration behaviors

\begin{tabular}{|c|c|c|}
\hline Dimension & Firm-centered & Consumer-led \\
\hline $\begin{array}{l}\text { Purpose of } \\
\text { Resource } \\
\text { Integration }\end{array}$ & $\begin{array}{l}\text { To develop/offer novel value propositions } \\
\text { (Vargo \& Lusch, 2008, 2016) }\end{array}$ & $\begin{array}{l}\text { To create value-in-use for themselves and/or for others (Vargo } \\
\text { \& Lusch, 2008) }\end{array}$ \\
\hline $\begin{array}{l}\text { Resource } \\
\text { Integration } \\
\text { Behaviors \& } \\
\text { Processes }\end{array}$ & $\begin{array}{l}\text { Cross-functional team-based processes for value creation } \\
\text { (Hughes et al., 2018); for example, automobile companies } \\
\text { establishing after-sales service and consultation processes } \\
\text { to resolve customer issues/complaints } \\
\text { Access to interactive platforms for collaborative ideation } \\
\text { (Busser et al., 2019); for example, Starbucks utilizing } \\
\text { crowdsourcing platforms to involve customers in new ser- } \\
\text { vice and product development } \\
\text { Educating participants to modify or enhance their capabilities } \\
\text { (Ng et al., 2016); for example, appliance brands providing } \\
\text { customers with product manuals, installation videos, repair } \\
\text { guides, and on-site demonstrations of their products } \\
\text { Establishing or reconfiguring institutional arrangements in the } \\
\text { service ecosystem (Barrett et al., 2015);for example, Airbnb } \\
\text { establishing the landlord(tenant) evaluation mechanism } \\
\text { to support generation of cumulative knowledge on their } \\
\text { performance }\end{array}$ & $\begin{array}{l}\text { Value-in-use for themselves: } \\
\text { Seeking information from social ties to satisfy one's needs } \\
\text { (Shah \& Tripsas, 2007); for example, consumer hobby- } \\
\text { ists gathering ideas from online communities and making } \\
\text { improvements on their own hobby equipments } \\
\text { Sharing information about one's needs to find the right solution } \\
\text { (Yi \& Gong, 2013); for example, software developers going } \\
\text { to the Stackoverflow platform and sharing details on specific } \\
\text { problems they are facing to find solutions from peers } \\
\text { Self-initiated or self-directed learning (Hibbert et al., 2012); } \\
\text { for example, consumers consulting instructions on a website, } \\
\text { reading tips on online forums and watching online videos to } \\
\text { repair appliances } \\
\text { Connecting with other consumers to obtain high-quality and } \\
\text { low-cost products/services (Jing \& Xie, 2011); for example, } \\
\text { consumers sharing the product link with several friends in } \\
\text { group buying to get more discounts for themselves } \\
\text { Value-in-use for others (peer consumers): } \\
\text { Selecting products that best meet the needs of peer consumers, } \\
\text { interpreting those products in ways that enhance their value- } \\
\text { in-use for peer consumers, and persuading peer consumers to } \\
\text { purchase those products (the current study) } \\
\text { Utilizing firm and consumer-owned resources to create new } \\
\text { resource combinations, constructing new value propositions } \\
\text { with such resource combinations, and uniting personal traits } \\
\text { with such value propositions to create unique brand identities } \\
\text { (the current study) }\end{array}$ \\
\hline
\end{tabular}

are regarded as fundamental resources owned by all social media influencers (De Veirman et al., 2017; Evans et al., 2017; Shan et al., 2019).

These and other personal operant resources may lead to different behavioral manifestations of influencers, which distinguish the roles they play in consumer-led resource integration and service innovation. Existing studies have indicated some of these roles of social media influencersfor example, persuasive opinion leaders who exercise strong influence on product purchasing and evaluation by followers (Shan et al., 2019) and creators who produce digital content and develop novel solutions to satisfy potential needs of niche consumer communities (Lanz et al., 2019). Yet there has been limited focus on identifying the dominant operant resources-i.e., personal operant resources that have a decisive influence on influencer roles - that assume relevance in service innovation in CSC.

More broadly, there has been limited discussion on the nature or type of social media influencers' dominant operant resources, the specific roles associated with these resources, and more importantly, how they affect service innovation outcomes. Drawing on the SDL perspective, here, we suggest that each lead role played by influencers (consumers) in service innovation essentially represents a different set of inputs-inputs that are related to the dominant operant resources of the role-that shape service innovation outcomes.

\section{Resource integration behaviors of actors in service innovation}

As noted previously, resource integration, which entails the assimilation and combining of specific operant and/or operand resources in particular interactions (Lusch et al., 2007), motivates and constitutes exchange (Vargo \& Lusch, 2008). Lusch and Nambisan (2015) stress service innovation as a collaborative process involving diverse actors engaged in resource integration. As SDL implies, both firms and consumers are resource integrators (Vargo \& Lusch, 2008). Table 1 shows firm-centered and consumer-led resource integration behaviors proposed by the existing literature.

Firm-centered resource integration behaviors are targeted at developing and offering novel value propositions (Vargo \& Lusch, 2008, 2016) and include team-based processes for internal and external problem solving, processes and platforms that promote collaborative ideation 
with customers and other external partners, and processes to educate and enhance the knowledge and capabilities of customers (Hughes et al., 2018; Busser et al., 2019; Ng et al., 2016). Another such behavior, from an ecosystem perspective, relates to establishing or reconfiguring novel institutional arrangements that leverage relational and knowledge resources in the service ecosystem (Barrett et al., 2015). These and other such actions enable firms to establish, lead and support efforts to integrate diverse types of resourcesfrom production materials and supply chain management technologies to relational ties with customers-and generate novel value propositions that meet unique market needs (Skålén et al., 2015).

Consumer-led resource integration behaviors involve efforts by individual consumers to create value-in-use for themselves and/or for others (Vargo \& Lusch, 2008). As shown in Table 1, typical behaviors identified by existing studies include sharing information about one's needs/problems to find right solutions, self-initiated or self-directed learning, and associating with other social ties (e.g., Shah \& Tripsas, 2007; Yi \& Gong, 2013). In most of these studies, the focus has been on consumers integrating resources to create value-in-use for themselves-either solving some problems in using products/services or modifying an existing product in ways that deliver more value-in-use, i.e., efforts that are largely limited to their current consumption experience.

Yet, as Hibbert et al. (2012) proposed, all consumers are not equal in unlocking value from their resource integration activities. Social media influencers imply the potential for consumers to integrate diverse resources (personal, interpersonal, or organizational) in ways that go beyond their current consumption experience and create value-in-use for peer consumers. For instance, social media influencers may directly or indirectly challenge existing forms of service by either changing the connections between firms and the community of consumers (Riviere et al. 2009), or developing customized interpretations of existing products and brands. They may also combine diverse resources including new media technologies, their own knowledge about the brand and their relational ties with the community of consumers to influence the way consumers learn about new products or brands (Dahl et al., 2015). All of these indicate novel opportunities for influencers (consumers) to integrate their personal resources with organizational resources and to initiate and lead service innovation initiatives that create valuein-use for peer consumers (Lusch \& Nambisan, 2015).

\section{The role of technology affordances in service innovation}

Existing research highlights digital technology as an important factor supporting or driving service innovation (Antons
\& Breidbach, 2018; Barrett et al., 2015; Nambisan et al., 2017). Within this context, social media assumes critical significance as the core technology of social commerce (Kaplan \& Haenlein, 2010; Li et al., 2021). Social media technologies have been defined as the set of Internet and other communication technology-based applications that facilitate social interactions and allow for the creation and exchange of user-generated content (Kaplan \& Haenlein, 2010). Typical SMTs include social networking tools (e.g., Facebook and WeChat), social publishing or sharing tools (e.g., TikTok and YouTube), social and content management tools (e.g., Moodle), and virtual worlds and gaming platforms (e.g., Twitch, WeeWorld).

To examine how SMTs enable resource integration by social media influencers for service innovation, we draw upon the technology affordance perspective (Markus \& Silver, 2008; Majchrzak \& Markus, 2012). An affordance exists when the properties of an object intersect with the ability and intention of a social agent (Cabiddu et al., 2014), and represents the action possibilities—or opportunities for action-offered to an individual by an object (Volkoff \& Strong, 2013). Technology affordances are relational and exist only in the context of the technology and the user's goal.

Table 2 shows the dominant perspectives of SMT affordance research. As is evident, much of the focus has been on studying the affordances associated with intra-firm interactions, i.e., to facilitate knowledge sharing and integration within the firm boundaries (Lee et al., 2019; Song et al., 2019; Treem \& Leonardi, 2013). A second set of studies have focused on SMT affordances associated with knowledge creation and sharing in firm-led interactions or engagement with consumers (e.g. Cabiddu et al., 2014; Tim et al., 2017). A third stream has focused on SMT affordances related to community interactions in non-commercial settings (e.g. Raja-Yusof et al., 2016). As is evident, there has been limited focus on SMT affordances associated with consumer-led resource integration and service innovation, i.e., activities wherein consumers (here, influencers) assume a lead role, actively integrate resources, and drive innovation and commercialization.

As affordance is a relational concept, the diversity of user's goals or technology application contexts will naturally lead to SMTs showing a variety of affordances. Here, we consider SMT affordances as the action potential of SMTs, as perceived by social media influencers, in the use context of resource integration for service innovation. Several SMT affordances may assume relevance in such a context. For example, social media promotes inter-group interactions and enhances interpersonal influence by enabling or facilitating the connections or relationships with consumer communities (association affordance; Treem \& Leonardi, 2013; Song et al., 2019); it may also afford influencers with the ability 
Table 2 Dominant perspectives of SMT affordance research

\section{Dominant Perspective}

Intra-firm interactions

Firm-dominant or firm-led interactions with consumers

Community interactions in noncommercial settings
Key Topics

Internal corporate communication, team work

Knowledge creation and sharing inside the organization

Knowledge creation and sharing outside the organization

Consumer engagement

Socializing and cyber-volunteering behavior

Brown and Michinov (2019)

Self-presentation and collaboration opportunities
Raja-Yusof et al. (2016)

McAfee (2009)

Gibbs et al. (2013)

Lee et al. (2019)

Pee (2018)

Faraj et al. (2011)

Shwartz-Asher et al. (2020)

Cabiddu et al. (2014)

Shao and Pan (2019)

Tim et al. (2018)

Chan and Holosko (2017)

Karahanna et al. (2018)
Majchrzak et al. (2013)
SMT Affordances

- Affordances to facilitate team work and internal corporate communication

- Affordances to facilitate informal interactions within the organization (employee social networks)

- Sample affordances identified:

Association; Visibility; Editability; Persistence

- Affordances to facilitate organizational knowledge creation and sharing (for example in product development)

- Sample affordances identified: Searchability; Tagging; Links; Authoring

- Affordances to facilitate knowledge sharing and collaboration in online communities

- Sample affordances identified: Reviewability, Recombinability, Experimentation

- Affordances to enable consumer engagement for two-way interactions

- Sample affordances identified: Persistent engagement; Customized engagement; Triggered engagement

- Affordances to enable the accumulation of social capital

- Affordances to enable individual involvement in enacting a task to achieve a collective objective

- Sample affordances identified: Socializing; Individualized affordance

- Affordances to enable self-presentation on the Internet

- Affordances to enable users to collaborate with each other to create content in a social media setting

- Sample affordances identified: Selfpresentation; Collaboration 
Table 2 (continued)

\begin{tabular}{|c|c|c|c|}
\hline Dominant Perspective & Key Topics & Representative Studies & SMT Affordances \\
\hline Consumer-led service innovation & Influencer marketing & The current study & $\begin{array}{l}\text { - Affordances to enable influencers' } \\
\text { connections or relationships with } \\
\text { peer consumers (followers) and } \\
\text { with cooperating firms } \\
\text { - Affordances to enable the digi- } \\
\text { tal presentation of influencers' } \\
\text { resources and capabilities } \\
\text { - Affordances to enable the finding, } \\
\text { acquiring, absorbing, and/or recom- } \\
\text { bining of heterogeneous resources } \\
\text { - Affordances to enable coordination } \\
\text { of complex, interdependent set of } \\
\text { activities/tasks involving multiple } \\
\text { actors (here, influencers and their } \\
\text { cooperating firms) } \\
\text { - Existing affordances referred: Asso- } \\
\text { ciation; Visibility } \\
\text { - New affordances identified: Explo- } \\
\text { ration; Coordination }\end{array}$ \\
\hline
\end{tabular}

to digitally present their resources and capabilities (visibility affordance; Treem \& Leonardi, 2013). Similarly, social media enables individuals (e.g., users) to collaborate with each other to create content in a social media setting (collaboration affordance; Davis et al., 2009; Karahanna et al., 2018). Therefore, social media influencers' perceptions regarding these and other action possibilities associated with SMTs will shape their affordance actualization behaviors (here, resource integration behaviors). Given this, it is critical to understand what specific types of SMT affordances assume salience in the consumer-led (here, influencer-led) resource integration context.

Our discussion of the theoretical background indicates that: (a) social media influencers possess heterogeneous personal resources that can be deployed to pursue service innovation; (b) service innovation in CSC is the outcome of resource integration by social media influencers, which goes beyond their immediate consumption experience and holds the potential for creating novel value-in-use for peer consumers; (c) social media influencers' perceptions of the affordances of SMTs drive their resource integrating behaviors. The case study described below builds on these theoretical insights and delves deeper into the specific roles and associated resource integration behaviors of social media influencers in service innovation in CSC.

\section{Research method}

\section{Case study design}

We employed a case study methodology to explore how social media influencers integrate resources to engage in and enable service innovation in CSC, given the lack of extensive empirical research on this topic. A case study methodology represents a suitable approach when the underlying concepts of a phenomenon (here social media influencers' resource integrating behaviors in service innovation) and their relationships lack clarity or call for richer descriptions (Graebner \& Eisenhardt, 2013).

We started with an initial investigation of six Chinese companies that engage with their social media influencers in different ways. Our review and analysis of the theoretical background provided the necessary grounding for the case study analysis. We approached these six companies with our research plan and got permission from two of them (Company A and Company B) to pursue extensive data collection, which included direct access to their interactions with social media influencers as well as to their internal documents pertaining to brand management and innovation.

Company $\mathrm{A}$ is a leading fashion brand specializing in South Korean fast fashion; it possesses excellent product development capabilities and develops 30,000 new products every year, surpassing Zara by a huge margin ${ }^{3}$. Such product development requires strong product marketing capabilities. To improve product marketing, Company A chose to cooperate with social media influencers who had a certain number of followers in niche consumer communities, usually ranging from 100,000 to $500,000^{4}$. These social media

\footnotetext{
3 This data was confirmed by our interviewees as well as by secondary data from mainstream media (Sohu Finance). Detailed information is available on the website (http://business.sohu.com/20151016/ n423384349.shtml).

4 According to our anecdotal evidence and industry surveys (e.g., Data source: https://baijiahao.baidu.com/s?id=165403870216847 $6122 \& w f r=$ spider $\&$ for $=$ pc;http://www.woshipm.com/it/3106822.
} 
influencers usually served various vertical markets with considerable market size, and they showed competence in turning their follower-based resources into commercial interests. They cooperated with Company A to jointly improve individualized product promotion, which co-created value for the key stakeholders. For Company A, the cooperation with these influencers enabled the company to maintain a high sell-through rate of new arrivals and to continuously disseminate its products through social marketing (and ultimately to promote the sales). Influencers get considerable sales commissions (usually $20 \%-30 \%$ of the total sales) or advertising fees (that varies based on the social media platform) as well as the opportunity to maintain or increase the number of followers with the help of quality products. For ordinary consumers (followers), individualized product promotions offered new interactive marketing experiences.

Company B is an Internet brand incubator that is committed to working with creative influencers in social media to co-create new brands ${ }^{5}$. It is particularly interested in creative influencers who are talented at serving underexploited niche markets and generating innovative solutions to satisfy their needs. They are influencers who can employ their personal creativity to initiate and contribute to new brand building efforts that also involve obtaining professional support from Company B for brand operations. Company B provides customized entrepreneurial support, including information technology, logistics and operational services, to their cooperating influencers. Since its establishment in 2014, Company B has cooperated with several such creative influencers, and it has successfully launched over 20 new brands in three years in various industries including clothing, accessories, luggage, cosmetics, and agricultural products. Many of these brands have now become highly distinctive and are beloved brands of niche communities in China. Through jointly owning this new brand, the influencers could share brand profits while also reaping a sense of personal accomplishment. Such influencer-led individualized brand building efforts also represent a new approach to branding in which new value propositions that precisely fit the needs of niche communities are developed.

\section{Footnote 4 (continued)}

html), the influencers with such follower resources have become a major force, working with companies in most industries.

5 According to our interviews, these new brands were jointly owned by Company B and its cooperating social media influencers (both parties bore a certain proportion of the investment and shared brand profits). However, Company B and its cooperating influencers have established a tacit understanding that community consumers should think that the new brands belong to the influencers, so as to fully differentiate their brands from other brands established by competing companies in the market. They believed this was a beneficial way for the new brands to gain recognition from niche communities.
Company A and Company B teamed up with different types of social media influencers to achieve two types of service innovations, thus presenting a strong contrast for our study. At the same time, while separate or independent companies, they belonged to the same corporate entity, which allowed for better control of the corporate background. To a certain extent, this reduced any external differences caused by the distinctive development background of each firm, thereby increasing the comparability of the two cases in terms of the processes and mechanisms of consumer resource integration.

After selecting the two case firms, we first asked the firms to list their social media influencers who worked well with them. Company A provided a list of 16 candidates. We screened them using two criteria. First, the selected influencers should be the main type that Company A cooperated with. According to a statement from Company A, social media influencers with 100,000 to 500,000 followers accounted for $95 \%$ of all cooperation between the company and influencers; the other $5 \%$ mainly were macro influencers with more than 500,000 followers, which are very costly for Company A. Second, the selected influencers should have a stable cooperative relationship with Company A, rather than just a one-time cooperation. Based on the above criteria, we selected five influencers for further investigation. Company B provided us with a list of seven influencers who had successfully created new brands with the firm. We screened them using two criteria. First, the brands co-created by the selected influencers and Company B should belong to different industries, which allowed us to refine those common behaviors in brand building without considering industrial differences. Second, the selected influencers must have participated throughout the brand building process, which ensures that the influencers play an active role and have an important influence on brand building. Based on these two criteria, we selected five influencers as our interviewees.

We obtained detailed observations on influencers' resource integration behaviors and their outcomes by interviewing managers at the two firms and their cooperating social media influencers. Enterprise interviewees (i.e., managers) offered us organizational-level descriptions of consumer resource integration processes and identified objective outcomes of service innovation, while influencer interviewees offered us with detailed examples of their personal resources and behaviors. Collecting data from both sides of the CSC context provided us with a comprehensive description of consumer resource integrating behaviors, enabling factors and the outcomes.

\section{Data collection}

The screening procedures described above left us with the two case study firms (Company A and Company B; 
see Table 3) and a total of 10 influencer interviewees (see Table 4). The research team adopted three methods-semistructured interviews, documents, and observations-to enable triangulation and complementarity of data. As highlighted by Yin (2009), no single method should completely overshadow the others; all have their own advantages and are complementary to one another. The different methods built a crucial foundation for recreating the processes and mechanisms of resource integration by social media influencers and for conducting a rigorous analysis of such processes and mechanisms.

Semi-structured Interviews The primary method of data collection was semi-structured interviews conducted with an incomplete script (Fontana \& Frey, 2000) that helped us to explore the behaviors and processes involved in the engagement of social media influencers. The interviews were conducted in Chinese by the research team (consisting of three to six Chinese scholars capable of capturing the precise meanings in the native expressions of the interviewees). To ensure accuracy of the collected data, most interviews were recorded verbatim (four influencer interviewees were unwilling to be recorded, as indicated in Table 3 with the sign घ) and then transcribed in Chinese. We provide additional details in the Data Analysis section on how we analyzed and coded the data.

The research team liaised with the participating firms to coordinate multiple interviews at regular intervals. This facilitated prompt analysis of the data and allowed for follow-up on key questions in subsequent interviews. During the interviews, we established contact with the interviewees to verify and complement any incomplete or contradictory information in a timely manner.

The research team conducted 39 interviews between November 2016 and December 2019. For Case A, 22 interviews were conducted, of which 17 interviews were with executives of Company A and five were with social media influencers. For Case B, 17 interviews were conducted, of which 12 interviews were with company executives and five were with social media influencers. On average, the semistructured interviews lasted between 43 and 58 minutes. All interviews were recorded digitally and transcribed by a professional transcription team, resulting in approximately 965 minutes of digital recording for Case A and 978 minutes of digital recording for Case $\mathrm{B}$.

Documents The research team accessed document files related to both firms, including both external documents (e.g., reports in mainstream and business media) and internal archives (e.g., promotional videos and PowerPoint presentations provided by the firms). We collected these data to support and complement our interviews. For example, 16 media reports, collected from CNKI.net (the most frequently used digital library by universities and colleges in China), provided sufficient information for understanding the marketing strategy of Company A, which helped the research team to better understand Company A's purpose and criteria for selecting influencers. Moreover, these documents helped us identify the communicator role of the influencers and their value in promoting products, thereby enabling the research team to further explore the specific behaviors of the influencers. The document files collected from both companies are described in Table 3.

Observations For the investigation of companies, the research team conducted four field visits to the headquarters of both companies between 2016 and 2018 (including the live streaming room specially designed for influencers and the work sites of major departments). The research team also attended the annual meetings of both companies in 2018 and an internal discussion on new brand building organized by Company B in 2019. We recorded key statements on marketing or brand development strategies shared in these meetings, and these data helped us to verify the benefits or performance of the influencers' cooperation with the case firm.

For the investigation of influencers, the research team observed the ten influencers through their short videos, public interview videos, and online live streaming shows, which were posted on popular social media platforms (like REDBOOK, TaoBaoLive, and Bilibili), and also attended the virtual communities to observe interactions between the influencers and their followers. We acquired key insights based on these observations. For example, in observing the short video of Miss Jin, we recorded what she said, her physical expression, and other elements (such as the popularity of the video, comments, and the number of thumbs-up and forwards). This allowed us to identify core concepts (like the persuading behavior) by analyzing the observed actions of the influencers as recorded in field notes and the statements made in interviews. Table 3 shows the observation data for the two cases.

\section{Data analysis}

To support the data analysis in the comparative case study design, we adopted the procedures recommended by Yin (2009) and Eisenhardt (1989) — that is, first conducting a single case analysis and then performing a comparative analysis. The open and axial coding strategies were used throughout the analysis, and the outcomes are depicted in Table 5.

In the single case analysis, we considered Companies A and B as two separate sample cases for independent analysis. Qualified researchers with qualitative data analysis experience were divided into two groups to independently code data for the two cases. The researchers attached preliminary codes to the case data and searched for key constructs 
Table 3 Data sources

\begin{tabular}{|c|c|c|c|c|c|c|}
\hline \multicolumn{2}{|l|}{ Cases } & \multicolumn{2}{|l|}{ Original Data Source } & \multicolumn{2}{|l|}{ Quantity } & \multirow{2}{*}{$\begin{array}{l}\text { Data Specifics } \\
\text { Group Vice President }\end{array}$} \\
\hline CASE A & Company A & Semi-Structured Inter- & First round, 2016 & 1 interview & $95 \mathrm{~min}$. & \\
\hline & & views & $\begin{array}{l}\text { Second round, } \\
\text { 2017-2018 }\end{array}$ & 13 interviews & $427 \mathrm{~min}$. & $\begin{array}{l}\text { Director of Product } \\
\text { Planning, Director of } \\
\text { Production }(2 *) \text {, Direc- } \\
\text { tor of IT, Manager of } \\
\text { IT, Manager of Product } \\
\text { Team A, Manager of } \\
\text { Marketing, Manager of } \\
\text { CRM, Group Leader of } \\
\text { Product Team B, Fash- } \\
\text { ion Buyer of Product } \\
\text { Team B, Picture Maker } \\
\text { of Product Team C, } \\
\text { Staff of Fabric Planning, } \\
\text { Staff of President's } \\
\text { Office }\end{array}$ \\
\hline & & & $\begin{array}{l}\text { Third round, } \\
2019\end{array}$ & 3 interviews & $152 \mathrm{~min}$. & $\begin{array}{l}\text { Group Vice President, } \\
\text { Operation Manager, } \\
\text { Director of Production }\end{array}$ \\
\hline & & Documents & Academic reports & 16 docs. & 224 pages & $\begin{array}{l}\text { Academic reports of } \\
\text { Company A from } \\
\text { CNKI.net (2011-2018) }\end{array}$ \\
\hline & & & Media news reports & 23 docs. & 90 pages & $\begin{array}{l}\text { Reports, speeches, and } \\
\text { news from mainstream } \\
\text { media platforms (2016- } \\
\text { 2019) }\end{array}$ \\
\hline & & & Annual reports & 2 docs. & 206 pages & $\begin{array}{l}\text { Annual company reports } \\
(2016-2017)\end{array}$ \\
\hline & & & Internal archives & 10 docs. & 97 pages & $\begin{array}{l}4 \text { promotional videos } \\
6 \text { internal PPT files }\end{array}$ \\
\hline & & Observations & Field notes & 1 meeting & 7 pages & $\begin{array}{l}1 \text { annual meeting on over- } \\
\text { all new product develop- } \\
\text { ment and marketing } \\
\text { (2018) }\end{array}$ \\
\hline & & & & 4 visits to the work site & 19 pictures & $\begin{array}{l}3 \text { visits to the corporate } \\
\text { headquarters (2017- } \\
2018 \text { ) } \\
1 \text { visit to the live stream- } \\
\text { ing room (2018) }\end{array}$ \\
\hline & \multirow{4}{*}{$\begin{array}{l}\text { Social Media } \\
\text { Influencers } \\
\text { (Partnering with } \\
\text { Company A) }\end{array}$} & $\begin{array}{l}\text { Semi-Structured Inter- } \\
\text { views }\end{array}$ & $\begin{array}{l}\text { First round, } \\
2017-2018\end{array}$ & 3 interviews & 186 min. & $\begin{array}{l}\text { Miss Jin, Miss Han, Miss } \\
\text { Liu‡ }\end{array}$ \\
\hline & & & $\begin{array}{l}\text { Second round, } \\
2019\end{array}$ & 2 interviews & $105 \mathrm{~min}$. & Miss Li, Miss Hę \\
\hline & & Observations & Field notes & 4 short videos & 43 pages & $\begin{array}{l}1 \text { short video of Miss Jin } \\
\text { (July 2018) } \\
2 \text { short videos of Miss } \\
\text { Han (July 2018) } \\
1 \text { short video of Miss He } \\
\text { (May 2019) }\end{array}$ \\
\hline & & & & $\begin{array}{l}2 \text { online live streaming } \\
\text { shows }\end{array}$ & 9 pages & $\begin{array}{l}1 \text { online live streaming } \\
\text { show of Miss Liu (July } \\
2018 \text { ) } \\
1 \text { online live streaming } \\
\text { show of Miss Li (May } \\
\text { 2019) }\end{array}$ \\
\hline
\end{tabular}


Table 3 (continued)

\begin{tabular}{|c|c|c|c|c|c|c|}
\hline Cases & & Original Data Source & & Quantity & & Data Specifics \\
\hline CASE B & Company B & $\begin{array}{l}\text { Semi-Structured Inter- } \\
\text { views }\end{array}$ & First round, 2016 & 2 interviews & $120 \mathrm{~min}$. & $\begin{array}{l}\text { Group Vice President, } \\
\text { General Manager }\end{array}$ \\
\hline & & & $\begin{array}{l}\text { Second round, } \\
\text { 2017-2018 }\end{array}$ & 4 interviews & $201 \mathrm{~min}$. & $\begin{array}{l}\text { General Manager, Deputy } \\
\text { General Manager, Gen- } \\
\text { eral Manager of Strategy } \\
\text { Department, Director of } \\
\text { Visual Group }\end{array}$ \\
\hline & & & $\begin{array}{l}\text { Third round, } \\
2019\end{array}$ & 6 interviews & $294 \mathrm{~min}$. & $\begin{array}{l}\text { General Manager, } \\
\text { Director of } 1^{\text {st }} \text { Strategy } \\
\text { Department, Director of } \\
3^{\text {rd }} \text { Strategy Department, } \\
\text { Staff of } 3^{\text {rd }} \text { Strategy } \\
\text { Department, Director of } \\
\text { Visual Group, Staff of } \\
\text { Visual Group }\end{array}$ \\
\hline & & Documents & Media news reports & 19 docs. & 66 pages & $\begin{array}{l}\text { Reports, speeches, and } \\
\text { news from mainstream } \\
\text { media platforms (2016- } \\
\text { 2019) }\end{array}$ \\
\hline & & & Internal archives & 4 docs. & 56 pages & $\begin{array}{l}1 \text { promotional video } \\
3 \text { internal PPT files }\end{array}$ \\
\hline & & Observations & Field notes & 2 meetings & 18 pages & $\begin{array}{l}1 \text { annual meeting on } \\
\text { overall group strategy } \\
\text { development (2018) } \\
1 \text { internal discussion on } \\
\text { new brand building } \\
\text { (2019) }\end{array}$ \\
\hline & & & & 4 visits & 25 pictures & $\begin{array}{l}4 \text { visits to the corporate } \\
\text { headquarters (2017- } \\
2019 \text { ) }\end{array}$ \\
\hline & $\begin{array}{l}\text { Social Media } \\
\text { Influencers }\end{array}$ & $\begin{array}{l}\text { Semi-Structured Inter- } \\
\text { views }\end{array}$ & $\begin{array}{l}\text { First round, } \\
2017-2018\end{array}$ & 2 interviews & $98 \mathrm{~min}$. & Mr. Song $₫$, Mrs. Wang \\
\hline & $\begin{array}{l}\text { (Partnering with } \\
\text { Company B) }\end{array}$ & & $\begin{array}{l}\text { Second round, } \\
2019\end{array}$ & 3 interviews & 265 min. & $\begin{array}{l}\text { Miss Liø, Ms. Liu, Mr. } \\
\text { Zhong }\end{array}$ \\
\hline & & Observations & Field notes & 2 short videos & 16 pages & $\begin{array}{l}1 \text { short video of Miss } \\
\text { Wang (July 2018) } \\
1 \text { music video of Miss Li } \\
\text { (Jan 2019) }\end{array}$ \\
\hline & & & & 3 interview videos & 15 pages & $\begin{array}{l}2 \text { interview videos of Mr. } \\
\text { Song (2017-2018) } \\
1 \text { interview videos of Ms. } \\
\text { Liu (2018) }\end{array}$ \\
\hline & & & & 1 field observation & 6 pages & $\begin{array}{l}\text { Invited into the virtual } \\
\text { community organized } \\
\text { by Mr. Zhong to observe } \\
\text { his interactions with his } \\
\text { followers. }\end{array}$ \\
\hline
\end{tabular}

*The number of interviews organized for one individual; $\sharp$ Interviewees who were unwilling to be recorded in interviews.

and emerging relationships. The coding schemes and code assignments were based on the study's core theoretical concepts and issues revealed from the literature review.
After the open coding of the two cases, the two groups of researchers continued to perform axial coding independently, incorporating the preliminary codes into organized sets, themes, or constructs to form first-order concepts 


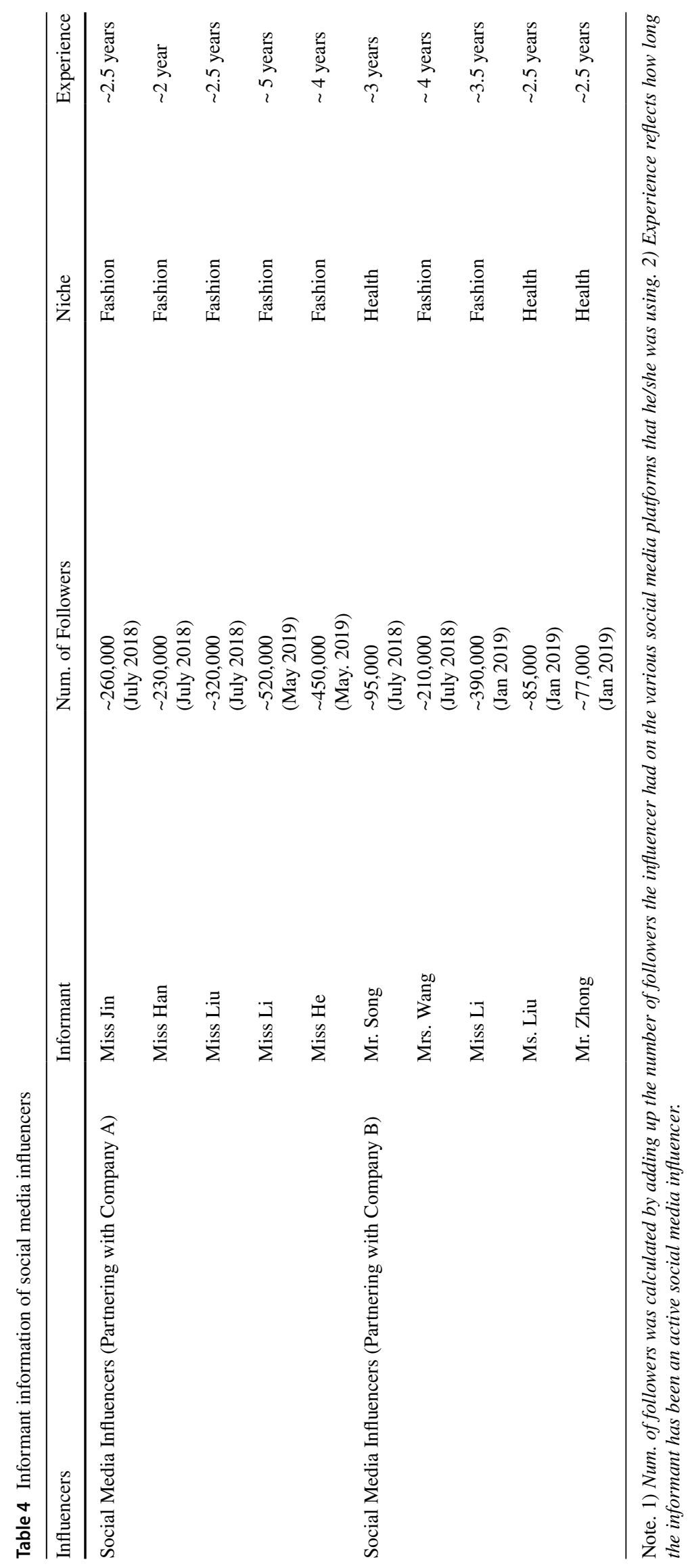




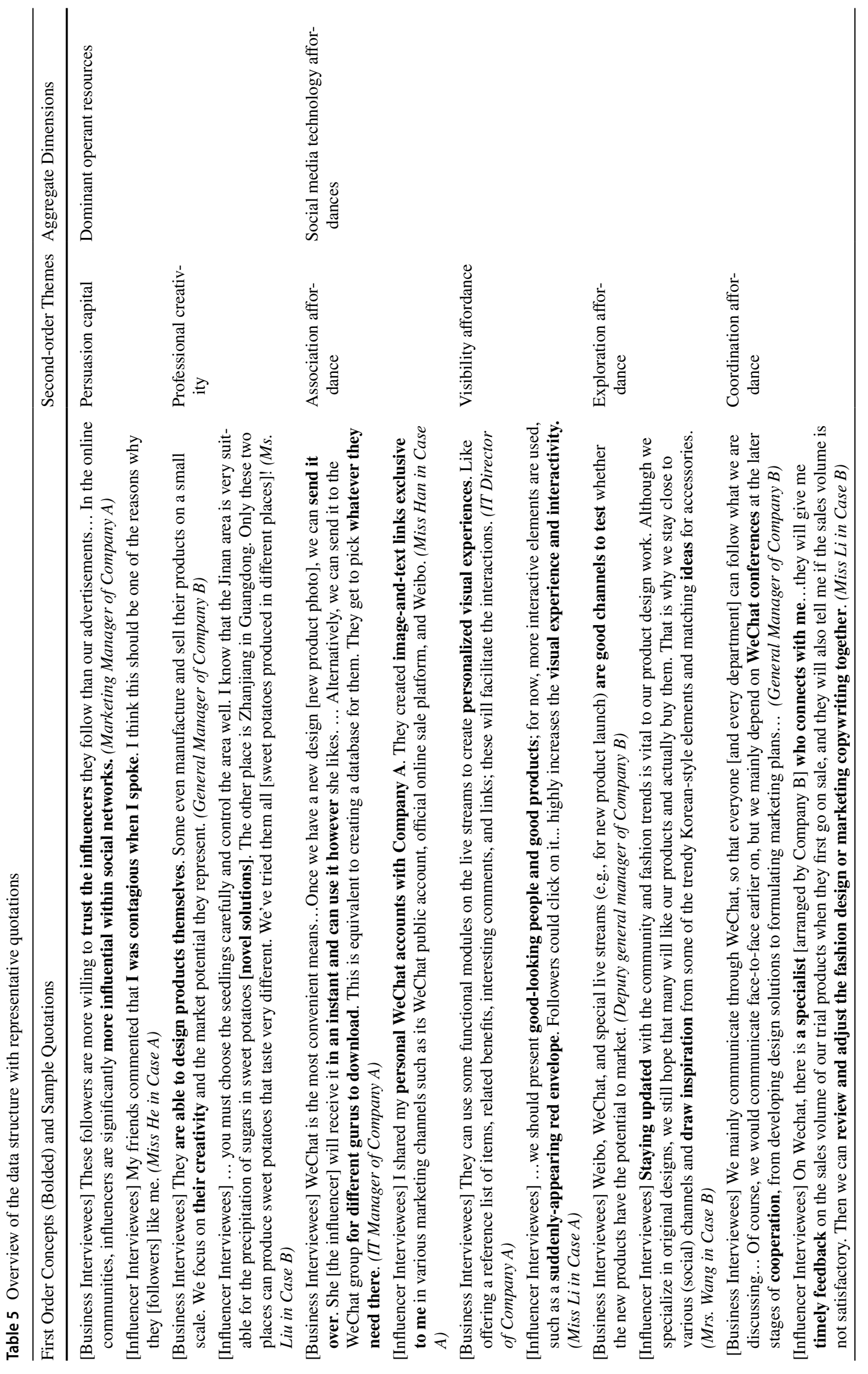




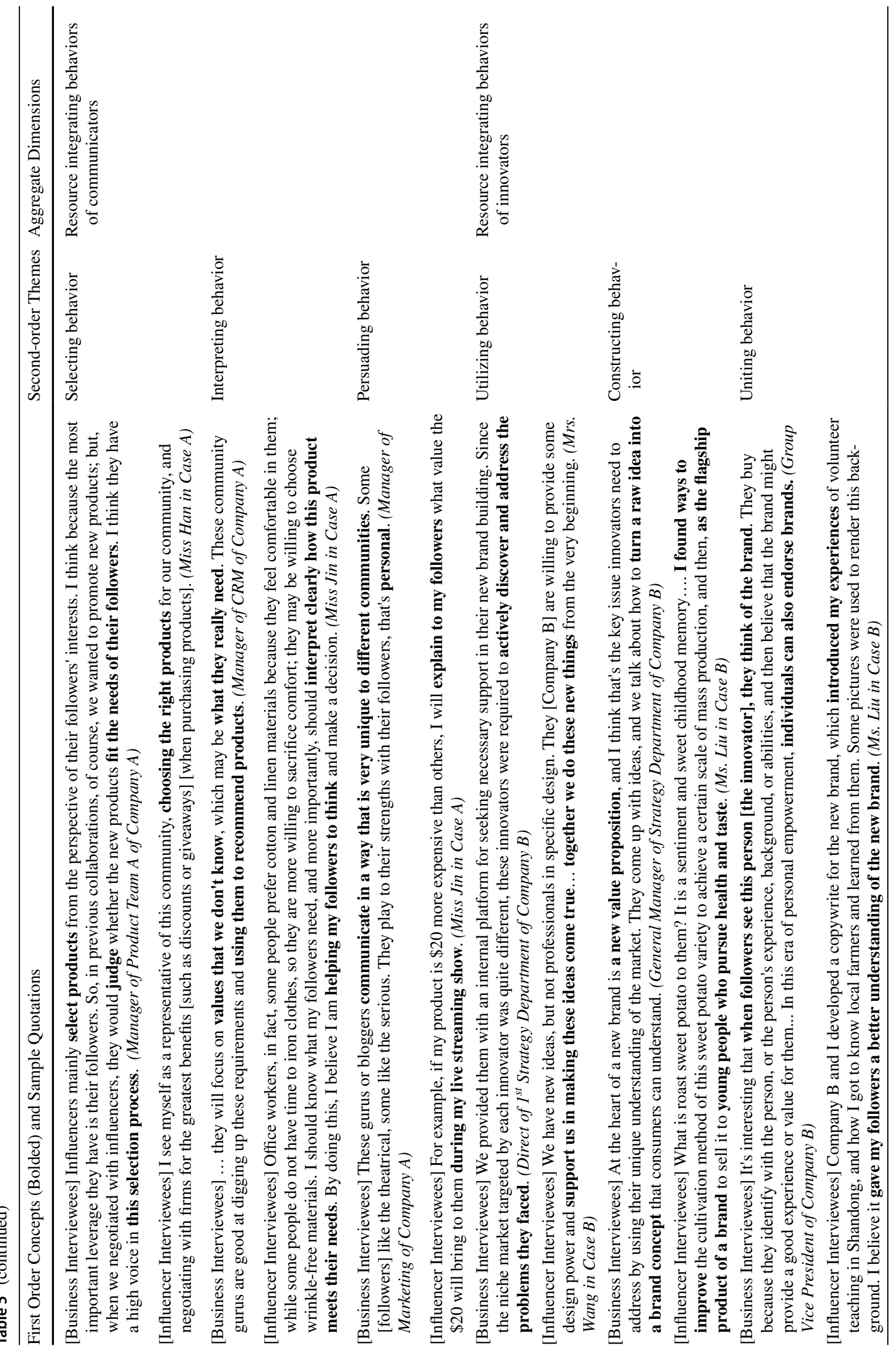


(Strauss \& Corbin, 1998). Subsequently, these two groups compared their coding results. Any inconsistency in the coding results was repeatedly discussed until consensus was reached. At this stage, we used new case data for comparison to further verify that the first-order concepts were complete. If these were not complete, the researchers revisited the data and replenished the open coding to form more rigorous first-order concepts. Based on the first-order concepts, the researchers generalized the second-order themes and drew on existing theories to form core concepts that describe the important phenomena and the research questions.

In the process of data analysis, we identified emergent concepts in our data and categorized them by juxtaposing them with those in the relevant literature (Suddaby, 2006). We first identified the relationships between the dominant operant resources owned by social media influencers and their perceptions regarding the action possibilities associated with SMTs. Then, as explained above, we used these relationships iteratively to code the data in more detail to identify the specific resources and technology affordances. In the same way, we identified the relationships between SMT affordances and their resource integrating behaviors as well as the relationships between resource integrating behaviors and service innovation outcomes. More labels were generated in detail based both on case evidence and previous research. As illustrated in Table 5, labels already in use in the scholarly literature on SDL-informed service innovation, social media influencer engagement, and technology affordances (such as "persuasion capital," "association," "selecting," and "persuading") captured some of our second-order themes well, whereas others required creating new labels (such as "interpreting," "constructing," and "uniting"). Detailed interpretations of all key labels are provided in our Research Findings section.

There was a language gap we had to cross in the data analysis. Considering that translating all data into English would be very expensive and time consuming, we chose to use Chinese in the open coding and English in the axial coding. To ensure the consistency of key concepts between our analysis and the published studies, we repeatedly went back to the existing studies to learn the typical language associated with social media, influencer marketing, resource integration, and service innovation. Therefore, all secondorder codes were labeled with both the Chinese terms and their corresponding English terms. This approach provided a good transition between the two languages and enabled us to further refine aggregate dimensions and build the conceptual model.

Equally important, to ensure credibility of the data, we adopted several well-established techniques outlined by Silverman and Marvasti (2008), Friend and Malshe (2016), and Johnson and Sohi (2016). Specifically, to ensure dependability, most of interviews were recorded digitally 
and transcribed, allowing different researchers to code the transcripts of each case independently. NVivo qualitative software was used to store, organize, and analyze the interview transcripts. The coding results of the researchers were compared; if disagreements occurred, discussions were organized to improve consistency. To ensure validity, we engaged in an iterative process of adding new data collected from additional interviews to the analysis until theoretical saturation was achieved. Findings were compared to the additional data and iteratively enriched until no new insights emerged. To further ensure interpretability, multiple relevant quotations from different respondents pertaining to the same category were compared. We introduced cases from other enterprises in the preliminary investigation to verify the core ideas and findings. The findings were consistent across the multiple contexts and cases assessed.

\section{Research findings}

Figure 1 illustrates the conceptual framework of resource integration by social media influencers in service innovation that was derived from the data analysis. This framework indicates that the social media influencers' roles (as reflected by their dominant operant resources) shape their perceptions regarding the action possibilities associated with SMTs (i.e., technology affordances), and that these perceptions, in turn, shape their resource integrating behaviors, which lead to specific innovation outcomes.

Our evidence led us to highlight two roles of social media influencers: the communicator role (the influencers in Case A) and the innovator role (the influencers in Case B). The communicators connect the products or brands of Company A with the community of consumers (i.e. their followers) to initiate individualized product promotion, while the innovators develop and offer differentiated and individualized brand designs for specific niche consumer communities. Each role essentially represents a different set of inputs or resources, which signifies how the role contributes to service innovation. The following sub-sections provide detailed evidence that supports this framework, and each element of the framework and their interrelationships (P1, P2, and P3) are explained. Table 6 provides interpretations of the communicator and the innovator roles as well representative labels for the key constructs and propositions in this framework.

\section{Dominant operant resources of social media influencers influencing SMT affordances}

Our evidence shows that the dominant operant resources owned by social media influencers, that reflect their roles and intentions to engage in service innovation, shape their perceptions regarding the uses of SMTs in resource integration. We comparatively analyzed Case A and Case B to identify two types of dominant operant resources, persuasion capital and professional creativity. In this section, we show how persuasion capital and professional creativity separately indicate the communicator and innovator roles, and how these resources impact actors' perceptions regarding the uses of SMTs (i.e., affordances) in resource integration.

\section{Persuasion capital and its impact on the association and visibility affordances of SMTs}

In Case A, the evidence showed that influencers cooperating with Company A possessed skills and capabilities that made peer consumers feel that they (influencers) are trustworthy and well-intentioned as well as influenced peer consumers' product-related purchase decisions and behaviors. Drawing on Harmeling et al. (2017), we refer to such operant resources, owned by these influencer communicators, as persuasion capital - the degree of trust, goodwill, and influence an individual has with other people within a community.

For example, Miss He mentioned that before working with Company A, she often shared fashion clothes suitable for young women, in the 20-25 age group, on social media platforms, and interacted with her followers by commenting on pictures of celebrities wearing clothes. This enabled her to gain many followers. She would honestly analyze the fabric characteristics and the advantages and disadvantages when recommending matching clothing. For instance, she once told her followers that some people regard pleats as a symbol of "elegance" or "style", but some people think that pleats on clothes are not beautiful. She then reminded her followers that if they didn't like wrinkles on their clothes, they should not consider buying that particular clothing product. For followers, her "honest" approach makes her seem more authentic and trustworthy, and thus, they are more willing to pay for her recommendations. As described by Miss He,

"My followers have told me that my recommendations are reassuring. They believed I would not always let them buy, buy and buy ... but more from their point of view, I only told them whether the product was appropriate."

Excellent persuasion capital can also be reflected in copywriting, oral expression, and physical attractiveness. For example, in our observations of the videos and live streams of the performances of the influencers cooperating with Company A, we found that they often were very good at expressing the important needs or concerns of followers in concise, kind and relatable ways. Specifically, in a livestream of Miss Liu, we saw her demonstrate a women's skirt in person. To describe the effect of this skirt, she said, "I feel like the heroine from a TV series", thereby, conveying 


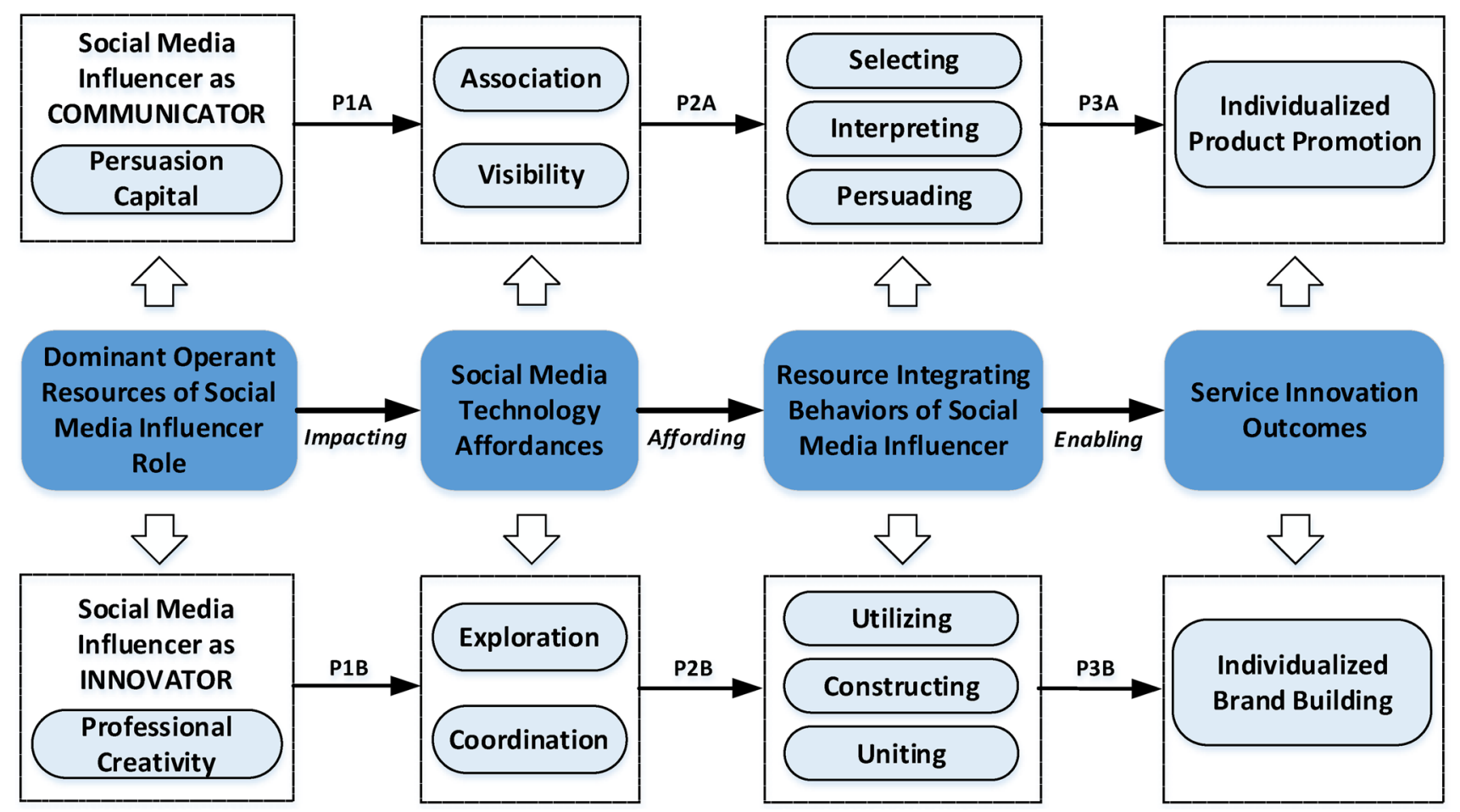

Fig. 1 A conceptual framework of resource integration by social media influencers in service innovation

to the viewer how this skirt can make the wearer more eyecatching. She turned her body around to show the details of the skirt, including laces, folds and suitable shirt matching. Her oral expressions and body language in introducing this product projected her empathy towards her followers as well as her trustworthiness.

Our evidence shows that, in Case A, persuasion capital impacted the perceptions of the influencer communicators in their use of SMTs. Specifically, since influencer communicators found themselves able to win the trust of followers and influence them (by exercising their persuasion capital), they tended to use SMTs (a) to maintain or facilitate their association with followers (e.g., interact with existing followers, or attract more followers), and (b) to enable their association with Company A (e.g., obtain business resources), both of which reveal the relevance of association affordance.

For example, influencer communicators used prevailing social commerce platforms (e.g., WeChat, Weibo, and TaoBaoLive) to post details about their personal daily life or to share their comments on specific products and those who were attracted by all this clicked on the 'follow' or 'like' button of social media, or bookmarked the live streaming link of the influencer to become their follower. Influencer communicators also used SMTs to regularly organize online community activities on specific topics to interact and maintain or strengthen their association with existing followers. Further, SMT features enabled them to classify and communicate with specific sets of followers that in turn strengthened their association with niche consumer communities. As Miss Jin noted,

"For example, many of them are office workers who don't have time to iron their shirts and prefer non-iron styles that won't wrinkle. From our interactions with them, we learned about their need to know whether the items of clothing are easy to care for. We pay particular attention to this point when choosing or promoting products."

Influencer communicators also used prevailing SMTs (usually WeChat) to build or maintain their connections with cooperating firms. For instance, in social media live streams, a communicator usually introduced a dozen products from different companies. Therefore, he/she needed to communicate with these cooperating firms (including Company A) in advance to confirm the copywriting (e.g., the selling point of a product) and specific show time of the selected products; through regular cooperation between Company A and their selected influencers, the company also provided comments and suggestions to the communicators after analyzing the promotion data to improve influencers' performance. As the cooperating firms were usually geographically dispersed, associations afforded by SMTs helped the communicators to effectively cooperate with different companies. 


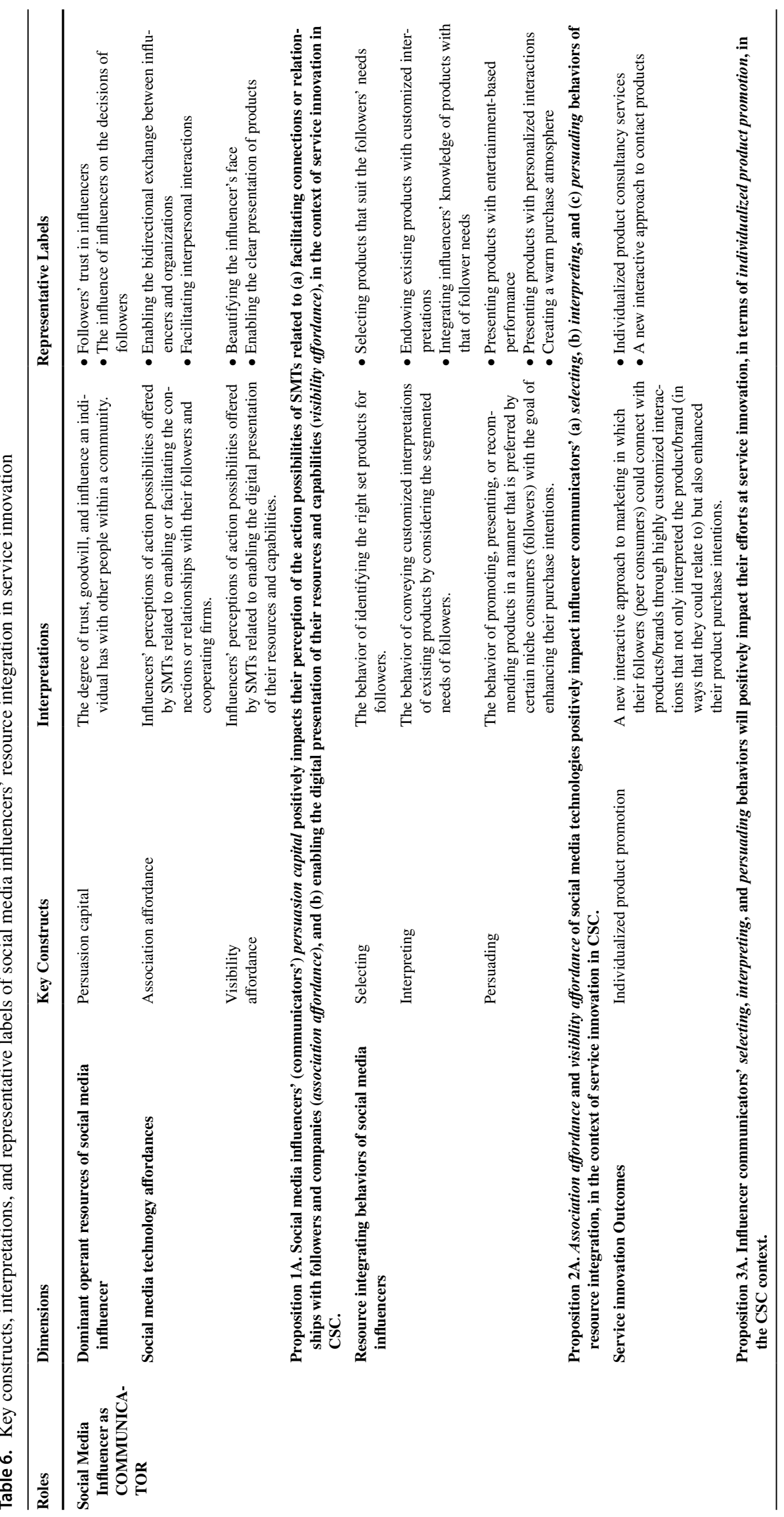




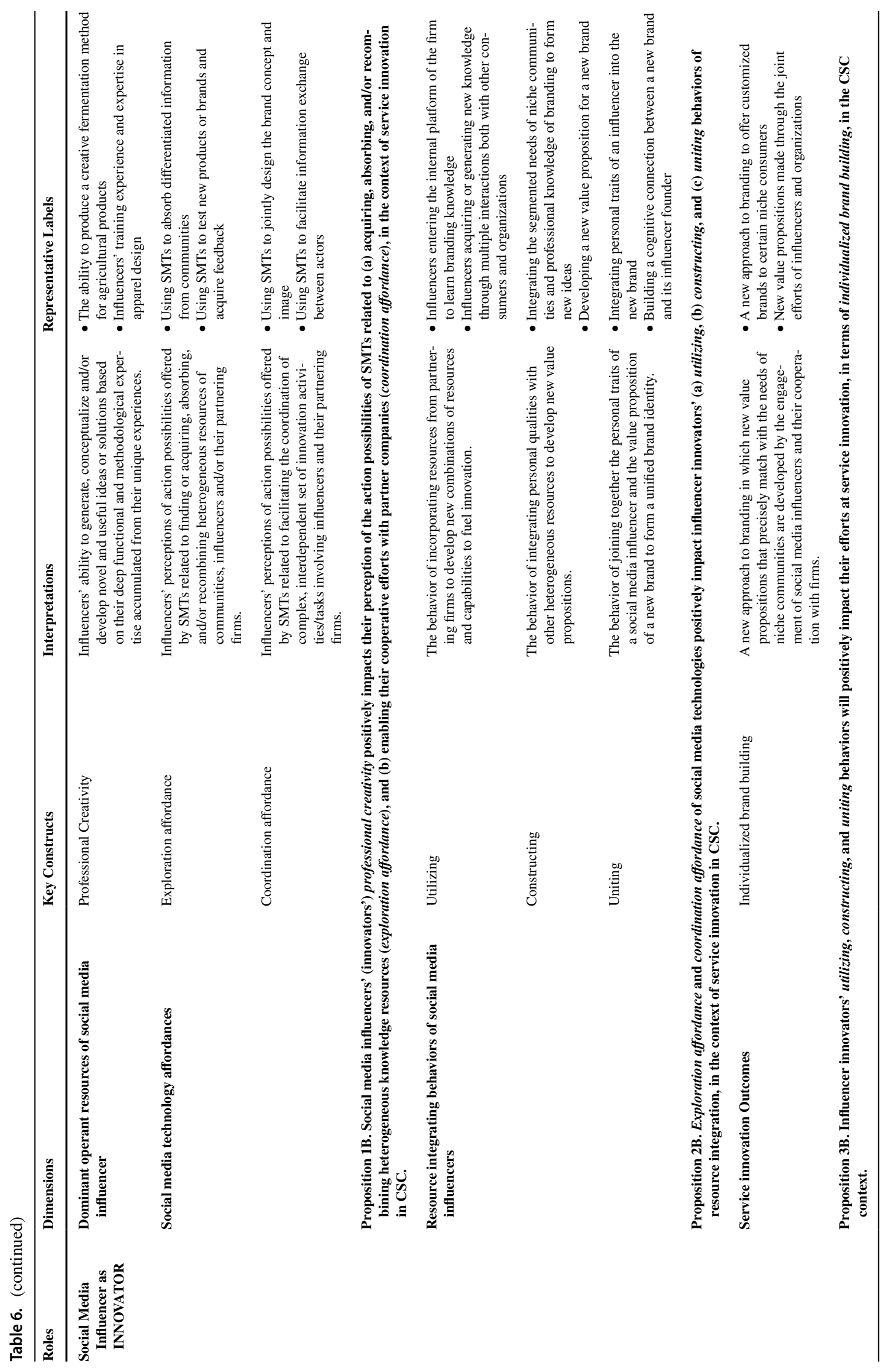


On the other hand, our case evidence shows that the influencer communicators regarded and used SMTs as a key tool to clearly present people and products, which reveals the relevance of visibility affordance. In terms of the presentation of people, for example, influencer communicators used filters embedded in the video and live streaming technologies to beautify the communicator's face such that consumers were able to enjoy a more satisfying visual experience. Similarly, funny and comical expression tools were used for entertainment-based performances and video plug-ins supported voice modification, which enhanced the amusement content. Such SMT-based visibility affordances enabled the communicators to appear livelier and to offer more appealing visual experiences to their followers.

In terms of product presentation, influencer communicators used new media technologies equipped with certain embedded and customizable technology modules to support individualized product presentation and interactions. For example, the influencer communicators cooperating with Company A inserted a custom information bar in the live streaming page. This information bar displayed the communicators' basic information, height, and weight as well as a list of that day's recommended products. It could be also used to highlight that day's offers and discounts. The communicators believed these visual applications were helpful to their communication and made them vivid and trustworthy to their followers. As stated by Miss Liu,

"These platforms are constantly innovating the plugins that help us better present products in the live streams. For example, several clothing offerings can be matched with each other in one live stream. When I recommend one of them, the corresponding or related outfits will be displayed at the bottom of the screen; followers can easily see these alternatives."

Based on the above findings, we suggest that:

Proposition 1A Social media influencers' (communicators') persuasion capital positively impacts their perception of the action possibilities of SMTs related to (a) facilitating connections or relationships with followers and companies (association affordance), and (b) enabling the digital presentation of their resources and capabilities (visibility affordance), in the context of service innovation in CSC.

\section{Professional creativity and its impact on the exploration and coordination affordances of SMTs}

In Case B, the evidence showed that influencers cooperating with Company B had the skills and ability to generate, conceptualize and/or develop novel and useful ideas or solutions based on their deep functional and methodological expertise accumulated from their unique experiences. Drawing on Petri and Jacob (2016) and Harmeling et al. (2017), we refer to such operant resources, owned by these influencer innovators, as professional creativity - i.e., creativity that is based on their own professional experience and knowledge. Different from the market-related knowledge resources (knowledge about followers, products, or brands) possessed by influencer communicators in Case A, we found that professional creativity possessed by influencers in Case $\mathrm{B}$ tends to be mostly related to their functional and methodological expertise.

Functional expertise can be understood as specialized knowledge within a function. For example, our interviewee, Mr. Song, was born in Shandong and has expertise in pear farming; Ms. Liu learned about sweet potato cultivation and its industry in detail through her volunteer teaching in Shandong; Mr. Zhong studied crop production and has been engaged in crop breeding and seed trade since his graduation; Both Mrs. Wang and Miss Li have been trained in apparel design and have mastered professional design abilities.

Methodological expertise relates to knowledge about specific techniques or methods to help structure a novel and useful solution. For example, Mr. Song's previous work experience exposed him to Japanese standardized farming techniques and allowed him to taste the delicacy of pears without pesticides, fertilizers or growth hormones. Because of his personal interest and enthusiasm for his hometown, after resigning from his job, he stayed in Shandong pear orchard every day, studied new farming techniques, and finally developed an organic fertilizer formula suitable for growing pear in the Shandong Province of China. In another similar example, Ms. Liu discovered a special sweet potato variety that was very suited to the tastes of young people. As she described, she devoted her time and effort to explore how to grow this type of sweet potato:

"To grow this type of sweet potato, you must choose the seedlings carefully and control the area well. I know that the Jinan area is very suitable for the precipitation of sugars in sweet potatoes. The other place [they can be grown] is Zhanjiang in Guangdong. Only these two places can produce sweet potatoes that taste very different. We've tried them all [sweet potatoes produced in different places]!"

Such professional knowledge and the associated creativity may not be relevant to an existing product to start with, and instead may gradually evolve in significance or become salient as the influencer discovers a novel market opportunity. As our interview with the deputy general manager of Company B showed, such personal background or experiencebased professional creativity has become crucial to innovate and cater to niche market demands: 
"Market demand, today, I mean, has become more refined to a significant extent. One brand is not enough to precisely satisfy the differentiated needs of different communities. Therefore, there is a great need to continuously develop new brands oriented towards niche markets ... We choose a feasible way to leverage the power of our influencers who have unique backgrounds to understand these niche markets. These innovators invest their resources to participate in the innovation of the entire brand ecology together with us."

Our evidence shows that, in Case B, professional creativity shaped the perceptions of influencer innovators regarding their use of SMTs. Specifically, our data indicates that influencer innovators made use of SMTs to acquire and process important information about unexplored consumer needs and to combine that with their professional creativity to develop novel ideas or innovative solutions that satisfied such needs. We refer to this as exploration affordance and define it as the action possibilities presented by SMTs related to finding or acquiring, absorbing, and/or recombining heterogeneous resources. Mrs. Wang, who had a flair for designing original Korean-style accessories, provided an example:

"Staying updated with the community and fashion trends is vital to our product design work. Although we specialize in original designs, we still hope that many will like our products and actually buy them. That is why we stay close to various (social) channels and draw inspiration from some of the trendy Koreanstyle elements and matching ideas for accessories."

Influencer innovators also used SMTs in their cooperation with Company B to experiment with or market-test new products or brands. For example, newly developed brands co-created by the innovators and Company B were first tested in small-scale online communities, usually the follower communities of the innovators. Click-based data and associated metrics offered by SMTs were used to provide instant feedback on the attractiveness and appeal of the new ideas. Further, followers' interactions and feedback were also analyzed to identify any unknown issues to design and to improve the brands.

Thus, exploration affordances offered by SMTs not only allowed influencer innovators to not only explore new market needs but also test the extent of fit of their innovative solutions vis-à-vis these needs.

SMTs allowed Company B and its influencer innovators to jointly design the brand concept and image by facilitating multi-media dyadic interactions. We refer to this as coordination affordance and define it as action possibilities presented by SMTs related to facilitating the coordination of complex, interdependent set of innovation activities/ tasks involving multiple actors or entities-in the current context, influencers and their partnering firms. ${ }^{6}$ For example, a WeChat group was created to facilitate the interactions among all relevant parties responsible for new brand building, where the innovators and Company B could share, exchange, and optimize ideas and design solutions. WeChat offered basic social functions, such as video chat and voice calls, and supported cloud meetings, which significantly facilitated multi-participant coordination of tasks.

Further, prevailing social media platforms (used by the influencers) were interfaced with Company B's big data enterprise information system (a production system based on a decision-making algorithm) that enabled precise management of production and inventory using data obtained from social media platforms (such as item sales and users' behaviors). This allowed influencer innovators and Company B to quickly come together and jointly evaluate their plans for new brands, including whether to offer discounts to slow-moving items. As Company B's deputy general manager indicated, using social media platforms integrated with internal big data systems was critical for efficient coordination of time-dependent tasks between the influencer innovators and the company:

"We capture different kinds of transactional and interactional data and purchase big data on the market from third-party platforms to obtain information that reflects market or product trends. This information tells us what the market needs, if we are doing the right thing, and what we should sell tomorrow and to coordinate all this decision making with our influencers."

Based on the above discussion, we suggest the following,

Proposition 1B Social media influencers' (innovators') professional creativity positively impacts their perception of the action possibilities of SMTs related to (a) acquiring, absorbing, and/or recombining heterogeneous knowledge resources (exploration affordance), and (b) enabling their cooperative efforts with partner companies (coordination affordance), in the context of service innovation in CSC.

\section{SMT affording resource integration by social media influencers}

Based on the comparative analysis of Case A and Case B, we find that the ways influencers perceive and use SMTs had

\footnotetext{
${ }^{6}$ Note that in contrast to collaboration affordance which relates to support for reviewing each other's inputs and creating new digital content in a collaborative manner in a social media setting (Karahanna et al., 2018; Davis et al., 2009), coordination affordance brings a sharp focus on the support provided to manage the interdependencies among different (online and offline) tasks undertaken by different entities in service innovation and the complex scheduling and execution of such tasks in a social media setting.
} 
a distinct influence on their resource integration behaviors. For the communicator role, we identified three SMT-enabled resource integration behaviors: selecting, interpreting, and persuading; and, for the innovator role, we identified three other resource integration behaviors: utilizing, constructing, and uniting. Next, we discuss these behaviors and relate them to SMT affordances.

\section{SMT-enabled resource integration behaviors of influencer communicators}

Selecting Influencer communicators serve as the medium between a firm's product/brand and target consumers. Our evidence shows that influencers are very focused on selecting products that best meet the unique needs of their followers from the many options offered by cooperating firms. We summarized such action-identifying the right set products for their followers-as the selecting behavior.

Our case evidence shows that both association affordance and visibility affordance of SMTs enable the selecting behaviors of the communicators. For instance, SMT affordances to renew/strengthen their association with diverse sets of followers become key to keeping track of the changing consumer preferences and needs and helping them to direct their attention to those products that have a close fit. As stated by Miss Liu, she was meticulous when it came to the selection of products. She would put great effort in screening the alternative clothing by learning about the materials, quality, and after-sales services before deciding to recommend a clothing item to her followers at a given time. She mentioned that,

“...product/service quality and the fitness to the segmented needs are very important for maintaining a significant following."

The director of production at Company A provided his interpretation of such influencer behaviors:

"Some cooperating communicators will only promote our clothing after trying them on for a period of time. They will select products that are most suitable for their followers before recommending the products to them. This ensures that the connections they make are most suitable or optimal for our products"

Moreover, as described previously, SMT visibility affordances facilitate clear and authentic presentation of people and products, which enables influencer communicators to select products efficiently. Visibility affordances also enable their interactions with partner companies, specifically in evaluating the alternative products. For example, Miss $\mathrm{Li}$ (in Case A) noted that she usually browsed a number of product options in advance through video chat and communicated the functions or selling points of products efficiently through the real-time display of alternatives, so as to narrow down the scope of alternatives that she could experience herself before recommending to her followers. All of these illustrate the positive impact that visibility affordances have on influencers' selecting behavior.

Interpreting refers to the behavior of conveying customized interpretations of existing products by considering the segmented needs of followers. Our case evidence shows that the communicators utilized their deep knowledge of followers' needs to endow the products or brands with new use value, thereby increasing their followers' willingness to buy. An interviewee from Company A gave the following example. For the same long-down coat, Company A's branding emphasized that it was "warm," "lightweight," and "trendy," whereas an influencer communicator placed greater emphasis on the fact that the coat could "cover one's body shape very well," and "hide bow legs". The fashion buyer of a product team from Company A noted:

"As a consumer, she [the influencer] knows that this piece of clothing can provide additional value to women with imperfect body types. These are aspects that we may not think of or may be inappropriate for us to emphasize in corporate publicity."

Moreover, to better display a piece of clothing, the communicators often had to provide explanations and demonstrations from multiple dimensions, such as body shape, dress code, personal experiences, product material, marketing offers, and brand history. Both association and visibility afforded by SMTs enable communicators to convey such customized interpretations of existing products effectively to their followers. For example, by using live streaming technologies, communicators could vividly show their followers how to match clothes. To illustrate the interpreting behavior of the communicators, Company A's marketing manager provided an example:

"For example, sometimes we only cooperate with them to promote a down coat and will only send them one down coat. These communicators will then design certain matching sets that look good to them, such as with a pair of jeans or matched with other brands... When we communicate with them, we will only inform them of the core selling points, but the communicators themselves will judge whether to use these selling points for publicity. They will give greater consideration from the perspective of their followers. We are, of course, very happy to support them in having their own space for expression and creation. This is very good for boosting sales."

Besides, clothing products have short iteration cycles, rapid product launches, and countless styles, making it expensive for firms to carry out a precise presentation of 
complex and diverse products for various consumer segments. Therefore, the use value of a clothing product as perceived by consumers will be highly limited if a firm relies only on corporate or brand advertising. Influencer communicators can employ SMT association and visibility affordances to interpret the use value in varied ways (e.g., with different matching schemes) to connect the product with different segmented needs.

Persuading refers to the behavior of promoting, presenting, or recommending products in a manner that is preferred by certain niche consumers (followers) with the goal of enhancing their purchase intentions. Our case evidence shows that influencers pay considerable attention to the use of entertainment-based performance and personalized interactions-that rely on SMT association and visibility affordances-when displaying or recommending products, so as to encourage followers to participate and to stimulate their purchase intention.

First consider entertainment-based performance. Our interviews and observational results indicate that the communicators' unique performance capabilities are very useful in helping them to promote products. From our observation of a live streaming show of Miss $\mathrm{Li}$, who cooperated with Company A, we found that she was good at highlighting product features using humorous but slightly exaggerated expressions. For example, after putting on Company A's branded clothing, she said in an extremely fast, playful, and infectious tone, while clutching her chest, "This is so pretty, this is so pretty! Sisters. This! Is! So! Pretty! You must surely lack such a dress!" Furthermore, some communicators also communicated with specific set of followers using language that reflected the culture of that group. The manager of marketing for Company A provided a vivid example to illustrate this. A communicator with whom Company A partnered was adept at using language from anime and manga to express her evaluation of certain products, such as by using the expression "Dedicate Your Heart" (from the manga Attack on Titan) to call on followers to take voluntary and concerted action.

The second aspect is presenting products with highly personalized interactions. Influencer communicators were equally adept at using new media technologies to create a sense of presence and participation to present and match clothing and to answer questions from individual followers. Followers could clearly see the expressions and actions of the communicators, who describe their journey of using or buying the product as if they were chatting with friends. In addition, live streams afforded a real-time and interactive venue and gathered hundreds of consumers to watch, raise questions, and interact, often creating an atmosphere of lively participation. Communicators made real-time adjustments based on the questions raised by their followers. For example, when asked by a follower, "What outerwear should this hoodie be matched with?" Miss He immediately repeated this question and replied,

"I suggest that if you want to look more chic, and not be old-fashioned, you can match it with a trench coat (at which point, she put on a light-colored trench coat and twirled once). This is a very trendy match. You can wear the hood on the outside (she pulled the hood of the hoodie from inside the trench coat, placed it on the outside and explained further). How does that look? Doesn't it have a slight college look? It looks very nice when matched like this."

When communicators stimulate followers' purchase intention through entertainment-based performance and personalized interaction, often some followers would purchase the product through the product purchase links embedded in social media. This can be used to persuade other followers. For example, after Miss Li displayed products in the Taobao live streaming platform, her followers could enter the product sales page and buy the product by clicking the purchase link. At this time, Miss Li interacted with her followers in real time by saying, "They have already bought [the product], there are not many left, you'd better hurry up!". Besides, for creating a lively purchase atmosphere, the communicators would negotiate with Company A whether they could provide limited-time discounts, offers, or giveaways, thus causing consumers to truly feel that "a lost opportunity never returns."

Based on the above discussion, we suggest that:

Proposition 2A Association affordance and visibility affordance of social media technologies positively impact influencer communicators' (a) selecting, (b) interpreting, and (c) persuading behaviors of resource integration, in the context of service innovation in CSC.

\section{SMT-enabled resource integration behaviors of influencer innovators}

Utilizing behavior relates to incorporating resources from partnering firms to develop new combinations of resources and capabilities to fuel innovation, and was found to be associated with both exploration and coordination affordances. Our case evidence shows that influencer innovators cooperating with Company B overcame their resource (e.g., knowledge) limitations by drawing on the company's resources and exploring new resource and capability combinations that contributed to the co-creation of new brands. For example, innovators could join and participate in the internal communication platform set up by Company B to entertain questions and answers about brand building. These SMT-based interactions became the venue for influencers to explore and 
do hands-on learning about new concepts related to branding. For example, as Ms. Liu stated:

"My doubt at that time was whether this product could be successfully incubated into a new brand. Through this platform [of Company B], online and offline communication with the experienced managers of the company, I learned that the market space of the product, value propositions, and corresponding promotion resources are critical for incubating a brand."

Similarly, SMT platforms also afforded conducting rapid testing with followers, thereby allowing influencers to explore the feasibility of new brand concepts.

Moreover, some influencer innovators would establish a new brand design and operations team with the help of Company B. When the innovators came up with a new idea, they communicated with professional designers in Company B. After being evaluated as a great idea, influencers could access more supportive resources from within the firm, including getting product designers and managers with brand promotion experience to join in. In this new brand team, innovators were the primary decision makers. In short, the coordination afforded by SMTs was crucial for influencers to act on their ideas. Company B also provided supportive resources, such as product packaging design and third-party logistics, to enable the design and launch of the new brand. As described by the innovator Mrs. Wang,

"We have some new ideas, but we are not professionals in specific design. They [Company B] are willing to provide some design power and support us in making these ideas come true... together we do these new things from the very beginning."

Constructing behavior refers to integrating personal qualities with other heterogeneous resources to develop new value propositions, and was found to be associated with both exploration and coordination affordances. Our case evidence shows that, in constructing new value propositions, matching the needs of niche markets was an important objective shared between Company B and its influencer innovators. Each innovator had a distinctive personality and professional creativity; such differences represented consumer communities with different niche requirements. Innovators could leverage SMTs to explore the needs of such niche communities from the consumer viewpoint and develop novel and useful ideas to match.

Nevertheless, as pointed out by the interviewees, these novel and useful ideas were not enough to form new value propositions; they also require in-depth description and a suitable expression of such needs through professional design. Thus, new value propositions regarding the needs of their followers must be co-created by the innovators and
Company B. And, this in turn, requires synergy between the innovators and Company B in terms of personal judgment of value propositions and organizational experience in brand building. In this process of cooperation, the innovators leveraged WeChat to share their unique experiences with the firm, such as their knowledge of followers' needs and expertise of product design. Meanwhile, Company B assigned employees with brand building experience to discuss with these innovators in WeChat virtual groups; and together they condensed such niche requirements, thus forming specific solutions for each value proposition. All of these indicate how the coordination afforded by SMT was crucial for influencers to work together with company B in constructing new value propositions. A vivid example cited by the general manager of the strategy department of Company B illustrates the significance of the coordination affordance of SMTs:

"The influencer who made long dresses knew why some shorter women prefer maxi dresses despite their height. According to her, some followers told her that they had a wider crotch and crooked legs and that long dresses could cover these features better. Not a lot of consumers would tell companies things like that... Through her continuous interactions over WeChat with our managers in different functions, we were not only able to explore alternative brand positioning and value propositions but also coordinate the actions needed to settle on the final brand slogan 'a long dress can change a girl's destiny.' Judging from the follower conversion rate, the outcomes were quite successful."

Uniting behavior refers to joining together the personal traits of a social media influencer and the value proposition of a new brand to form a unified brand identity. Our data shows that both exploration and coordination affordances enable such behavior. For example, one of our influencer informants (Ms. Liu) mentioned how she used SMT to acquire followers' impressions of her by initiating a tagging campaign in her virtual follower community. This event made her realize that many of her followers trust her mainly because of her past experiences of volunteer teaching in rural areas in Shandong and her ability to discern the quality of local agricultural products. "Because I have these related experiences, it is easier for my followers to understand the value of the new brand that I want to deliver to them." Therefore, she communicated to the professional brand design team of Company B about the idea of incorporating her own personal characteristics into the brand design. After much discussion, Ms. Liu and Company B decided to name the new brand "Yi Mu Di Gua" (Chinese, it means "One Acre-feet Sweet Potato"), and to position the brand as a sweet potato brand serving health-conscious young consumers and families. As Ms. Liu stated, 
"I remember we were very pleasantly surprised at that time [in 2017]. Many of my followers left messages to say they liked our ideas, loved the new brand and our sweet potatoes. They told me that our sweet potatoes tasted so good that this product had changed their stereotype about sweet potatoes, which had been recognized as a food that the older generation had to eat in famine years."

This improved consumers' understanding of the new brand and its value proposition by drawing on their familiarity with the influencer innovator's personal traits/image or unique personal history. Further, the case evidence also shows that the coordination afforded by SMTs supported such uniting behavior. For example, in the above case, the influencer innovator and Company B coordinated and organized a series of market promotion activities using the prevailing social media platforms to emphasize the connection between the brand identity and the influencer profile.

Thus, based on the above discussion, we suggest that:

Proposition 2B Exploration affordance and coordination affordance of social media technologies positively impact influencer innovators' (a) utilizing, (b) constructing, and (c) uniting behaviors of resource integration, in the context of service innovation in CSC.

\section{From resource integration to service innovation}

Our study data also reveal that the resource integration behaviors of social media influencers afforded by SMT contributed to different service innovation outcomes.

\section{Individualized Product Promotion}

In Case $\mathrm{A}$, the data indicates that influencer communicators offered a new interactive approach to marketing in which their followers (peer consumers) could connect with products/brands through highly customized or contextualized interactions that not only interpreted the product/brand (in ways that consumers could easily relate to) but also enhanced their product purchase intentions. For example, in social media live streams, influencers engaged with and entertained their followers, and in the process, connected them with new products in ways that made sense in consumers' own use context. Recall Miss Liu's effort to show alternate matching outfits while promoting a clothing product in a live stream; such efforts help individualize product promotion in ways that most companies cannot do. As the group vice president of Company A noted:

"Regardless of whether a firm is an online store [like

Taobao] or a mobile store, its marketing approach is highly limited by corporate identity. Many companies are trying to cooperate with social media influencers to break this restriction. Take live streams as a typical illustration of this kind of real-time interactive store, performed or operated by social media influencers ... it allows products to be presented in more diverse ways."

Moreover, conventionally, it is expensive for firms to provide such diverse and individualized marketing services to cater to numerous niche consumer communities. The resource integration behaviors of influencer communicators-specifically, their selecting, interpreting, and persuading behaviors-not only enabled bringing the right consumer in contact with the right product but also ensured that the product-related information was conveyed in a way that was aligned with their immediate use context and would persuade them to purchase the product. Based on this discussion, we suggest:

Proposition 3A Influencer communicators' selecting, interpreting, and persuading behaviors will positively impact their efforts at service innovation, in terms of individualized product promotion, in the CSC context.

\section{Individualized brand building}

In Case B, the resource integration behaviors of influencer innovators - specifically, their utilizing, constructing, and uniting behaviors-led to the development or co-creation of original brands that precisely matched with the needs of niche consumer communities. As Company B's general manager noted, a key task is for the influencer to complement his/her personal (knowledge) resources with the right set of resources from the company.

"We cooperated with an influencer to build a successful original brand specializing in selling Hosui pears. These pears sold well because he [the influencer, $\mathrm{Mr}$. Song] used natural resources specific to his hometown in Shandong and a farming technique researched, developed, and modified by himself. This improved the texture substantially, and the pears taste silky-smooth, like milk. He spent three years hand-picking the seed variety and plantation location and invented the 'milk plus brown sugar plus white sugar' golden-ratio fermentation method. Importantly, he also combined his unique product-related knowledge with resources that we offered related to packaging, logistics, and promotion in turning his idea into a new brand that fit well with his follower base." 
Indeed, bringing to life such new original brands also requires coming up with novel value propositions that reflect the influencers' deep understanding of their followers' needs and desires, and importantly, uniting that with the influencers' own personal traits to ensure that the brand identity aligns well with followers' perception of the influencer. In the above case, the brand identity was built on Mr. Song's authenticity and quality consciousness that attracted his followers in the first place. As Company B's deputy general manager noted:

"The creation of the Yi Mu Di Gua brand is not an individual case. This shows that the personal traits of the innovators are extremely important to the success of the brand. I think that it is easier for followers to establish a sense of identification with the personal traits of these innovators."

Thus, we suggest:

Proposition 3B Influencer innovators' utilizing, constructing, and uniting behaviors will positively impact their efforts at service innovation, in terms of individualized brand building, in the CSC context.

\section{Discussion}

\section{Theoretical contributions and implications}

This study focused on how social media influencers integrate resources to engage in and enable service innovation in CSC. Our case study findings and the conceptual framework contribute towards deepening the theoretical understanding of consumer-led resource integration and value creation via social media and hold several important implications for future research in the broad area of service innovation. We discuss these in detail below.

\section{Lead roles of consumers in service innovation}

As noted previously, existing studies connecting consumers with service innovation from a resource integration SDLperspective have largely focused on their role as passive participants in the innovation process (Hollebeek et al., 2019), wherein the firm assumes the lead role and consumers assume a supportive role (Grönroos, 2012). Even the few studies that have considered consumer-led resource integration have focused on only those contexts where consumers create value-in-use primarily for themselves. Our findings suggest that service innovation may also be initiated and led by consumers, particularly, those who own (or control) relevant heterogeneous resources and can integrate diverse resources, to conceptualize, develop and deliver new valuein-use to peer consumers (i.e., new services that meet the needs of specific set of consumers in CSC). More broadly, our study contributes towards addressing two related issues - in what specific ways do consumers assume lead roles and engage in resource integration and service innovation targeted at peer consumers, and further, when (or, under what conditions) do they assume these lead roles - that help extend research on consumer-led service innovation.

First, our study findings and conceptual framework suggest that consumers (here, influencers with medium-sized followings) select or enact at least two lead roles-as communicator and as innovator- in service innovation. As communicator, they reinterpret the value-in-use of products/ brands and persuade peer consumers to purchase those products, and more broadly innovate in terms of individual product promotions. As innovator, they envision and construct new value propositions targeted at the unique needs of niche consumer communities, thereby building or developing individualized brands. In both roles, consumers (influencers) initiate and lead service innovation and go beyond their own immediate consumption experience to create value-in-use for peer consumers. As such, these findings complement and extend prior studies on consumer roles in service innovation.

Our study findings also indicate that influencers assume these lead roles based on the type of dominant operant resource they possess. Specifically, the study indicated the salience of two types of consumer-owned operant resources, persuasion capital and professional creativity. It is the presence of such operant resources (Lusch \& Nambisan, 2015) that spark innovation activities on the part of consumers. Our findings imply that when influencers possess at least one of these two operant resources, they are likely to initiate service innovation in the CSC context. On the other hand, when consumers possess only operand resources (for example, information on their own needs), they are more likely to assume a supportive or participant role in firm-led innovation.

Prior studies have noted that because of the dynamic and contextualized features of value (Barrett et al., 2015), it is important to identify critical operant resources in a specific context (Hughes et al., 2018). In other words, it is the salience of an operant resource vis-à-vis a service innovation context that determines in what way an influencer will add value (Hibbert et al., 2012). For example, although influencer communicators may also have possessed professional creativity, such an operant resource was not salient for individualized product promotion. Similarly, not every influencer who owns professional creativity can influence the purchasing decisions of others, which requires persuasion capital. It should also be noted that the presence of operant resources forms only a necessary and not a sufficient condition for consumer-led service innovation. As our study 
indicates, influencers must get access to additional resources and support infrastructure (e.g., social media technologies) to effectively employ their operant resources for innovation.

Further, while our focus here was limited to social media influencers, the findings imply the need for future research to identify other such operant resources that consumers might possess in different industry/market contexts that, in turn, may trigger new forms of consumer-led service innovation. By identifying additional types of operant resources possessed by influencers, future research may help develop a more comprehensive understanding of the entire landscape of innovation opportunities that can be exercised by social media influencers.

Finally, our study revealed that these two lead roles in service innovation are closely related to the uniqueness of the CSC context-one in which there are many niche consumer communities and social media influencers form critical hubs to connect with these communities. Further, the type of influencers we focused on here (those with medium-sized followings) and the nature of their partnership or cooperation with firms may also have shaped the roles we identified. All of these, in turn, imply the need for future research to adopt a more grounded approach —one that takes into consideration the specific marketing context as well as the characteristics of the consumer-to identify potential consumer lead roles in service innovation.

\section{Consumer resource integration behaviors in service innovation}

While prior studies have adopted the SDL perspective to examine resource integration behaviors in service innovation, the primary focus has been on either firm-centered resource integration or consumer-led resource integration within the limited context of creating value-in-use for themselves. Our study departs from such foci and highlights six resource integration behaviors that social media influencers exhibit in the pursuit of innovation and commercialization in the context of CSC. These six behaviors contribute towards developing an understanding of the micro-foundations of consumer-led service innovation, i.e., consumer-led resource integration primarily focused on creating value-in-use for others. This also responds to recent calls to generate more fine-grained knowledge of the process of creating service innovation (Gustafsson et al., 2020).

From a partnering firm's perspective, such an understanding of resource integration behaviors-whether it be on the part of consumers or other external actors in the service ecosystem-is critical to ensure that it adopts measures to support those behaviors. For example, in the case study, we found how companies can help craft product discount plans that influencers could use during live streaming to persuade hesitant consumers to purchase the product. Similarly, companies can offer their data analytics infrastructure to support influencers' efforts at testing new brand concepts among their followers. Future research that focuses on these and other micro-processes that underlie resource integration by consumers may offer critical insights on how a company's strategies and practices may facilitate its service innovation. More broadly, our findings on consumer resource integration behaviors imply how companies can make the shift from 'how to involve consumers in the process of service innovation' to 'how to cooperate with consumers to achieve service innovation' (Carlborg et al., 2014).

Further, by emphasizing a focus on influencers' resource integration behaviors, our study also implies the potential to inform on the evolution of influencer roles in service innovation. Specifically, by engaging in resource integration behaviors associated with one role (connected to one dominant operant resource), influencers may also get the opportunity to acquire or build new operant resources, thereby enabling them to assume additional roles in service innovation. For example, by continuously engaging in selecting, interpreting, and persuading behaviors within a niche consumer community, influencer communicators may be able to enhance their stock of professional expertise and creativity in a vertical market, allowing them to play the role of an innovator in the future. Similarly, by developing new brands with novel value propositions, influencer innovators may be able to attract new sets of followers and enhance their persuasion capital, enabling them to assume the communicator role in the future. While such evolution in influencer roles was not a focus of the current study, the operant resource and behavior (process) -based framework proposed here could provide the theoretical foundation for future research on the evolution of social media influencer roles in marketing and service innovation.

\section{SMT affordances in service innovation}

As discussed previously (Table 2), existing studies have paid limited attention to the powerful enabling role of SMTs in consumer-led service innovation. As our study of influencers indicates, the subversive impact of SMTs on individual consumer's innovation resources and capabilities has changed the power asymmetry between consumers and enterprises in the CSC context. By drawing on the notion of SMTs affordances, this study contributes to developing a more nuanced understanding of how individual consumers (here, influencers) can leverage new technologies to employ their unique personal resources and capabilities in service innovation.

Importantly, we found that the differentiated goals and resources of influencers (i.e., different roles) determine the way SMTs will be used by them in service innovation. For example, communicators are qualified with persuasion capital, so they tend to use SMTs to create and maintain/ 
strengthen interpersonal relationships with followers. Similarly, innovators, who are qualified with professional creativity, tend to use SMTs to coordinate the development of new ideas and solutions with their followers and organizations. The affordance perspective implies that an understanding of consumers' unique resources and goals is required to know how they would likely employ the power of SMT to engage in innovation. More broadly, the complex interplay between consumer resources/goals and SMT features could lead to more diverse innovation outcomes from the service ecosystem.

Our study also contributes to technology affordance research by identifying SMT affordances that assume relevance in the service innovation context. Prior studies have identified several SMT affordances, albeit only in the context of intrafirm interactions and firm-led interactions with consumers. The current study found that some of these affordances (e.g., association, visibility) assume relevance in consumer-led service innovation context too. At the same time, the study also identified two new SMT affordancesexploration and coordination - that, to our knowledge, have not been considered before. In turn, these findings imply two things. First, it implies the promise of extending the study of technology affordances to newer innovation contexts (e.g., innovation ecosystems) and identifying new types of SMT affordances. Second, our framework also indicates the opportunity to connect other types of SMT affordances mentioned in the literature (e.g., experimentation, triggered engagement) with new roles in consumer-led service innovation.

Finally, prior research on SMT affordances have not adopted a resource-integration perspective as the focus has been only how they enable different types of interactions. By linking SMT affordances with specific consumer resource integration behaviors, our framework also implies the need to focus on the varied behavioral consequences of specific types of technology affordances, particularly in the context of consumer-led service innovation.

\section{Managerial implications}

In today's world, the combination of the fragmentation of social media and the emergence of social referral as the primary way for consumers to reach products/brands has made it difficult for enterprises to serve a large number of niche markets simply by relying on internal resources and capabilities. According to the Digital Marketing Trends Report ${ }^{7}$, $72 \%$ of brand owners said they would increase influencer marketing investment, and $63 \%$ of them said that the focus will be on influencer-based promotion. Similarly, nearly

\footnotetext{
7 Data source: https://www.winchinamarket.com/g/97.html. (Accessed July. 2020).
}

$78 \%$ of large firms are inclined to innovate their products or brands by harnessing consumers' creative ideas and resources (Wang et al., 2019). Yet, there is limited understanding of how exactly firms can engage with social media influencers to drive service innovation.

Our study findings provide practical suggestions for these companies. Specifically, when attempting to create product promotions targeted at niche consumer communities, managers should consider using social media influencers with relevant persuasion capital. Firms should also deploy or provide access to social media platforms that offer features related to association and visibility affordances, given their role in enabling the resource integrating behaviors that underlie the communicator role. When managers attempt to build original brands targeted at niche consumer communities for long-term competitiveness, they should employ social media influencers with relevant creativity resources, allowing them to engage deeply in brand building and put their personal resources into play. They should also emphasize SMT features that are intimately tied with exploration and coordination affordances given their role in enabling the appropriate resource integrating behaviors.

More broadly, our study findings and framework imply that companies should carefully consider their desired innovation outcomes in developing strategies to partner with social media influencers and incorporate specific measures to facilitate their resource integration behaviors.

\section{Limitations and future research directions}

Our study has a few limitations that need to be pointed out. First, we focused here on two firms that achieved individualized product promotions and brand building as their respective service innovation outcomes. Given the high contextspecificity feature of consumer engagement (Brodie et al., 2011; Hollebeek et al., 2019), differences in such outcome dimensions affect the roles of influencers in engaging in service innovation. Further, our focus here was limited to social media influencers with medium-sized followings who were actively cooperating with focal firms. Future research may validate our framework outside these two boundary conditions as well as identify additional influencer roles and their corresponding service innovation outcomes in other market and influencer contexts (for example, micro influencers, influencer entrepreneurs). Second, there may be differences (not captured here) between our two sample firms that shaped influencers' resource integration behaviors. For example, the nature of the institutional arrangements and/ or the enterprise information systems could impact actors' resource integration in service ecosystems (Barrett et al., 2015). Future studies may incorporate such contextual factors and adopt an ecosystem-centric view rather than the influencer-centric view employed here. Third, our focus 
here was on SMTs frequently used by both firms and their influencers. However, other emerging technologies, such as big data analytics, artificial intelligence, and augmented/ virtual reality may also play a crucial role in value co-creation. Future research should incorporate a broader focus on such digital technologies, which may help reveal additional technology affordances relevant in influencer-led service innovation. Finally, this study adopted qualitative data from China. Since China's Internet censorship is more extensive and advanced, it may impact influencer resource integration behaviors, such as their access to and use of globally available digital knowledge resources. Future research that examines influencers' resource integration behaviors in other geographical regions/countries or cultural backgrounds may help in generalizing the findings from the current study.

Acknowledgements This research is funded by research grants from National Natural Science Foundation of China (Grant \# 71802204, 71832014 and 72032009).

\section{Declaration}

Conflict of Interest Statement The authors declare that they have no conflict of interest to this work.

Open Access This article is licensed under a Creative Commons Attribution 4.0 International License, which permits use, sharing, adaptation, distribution and reproduction in any medium or format, as long as you give appropriate credit to the original author(s) and the source, provide a link to the Creative Commons licence, and indicate if changes were made. The images or other third party material in this article are included in the article's Creative Commons licence, unless indicated otherwise in a credit line to the material. If material is not included in the article's Creative Commons licence and your intended use is not permitted by statutory regulation or exceeds the permitted use, you will need to obtain permission directly from the copyright holder. To view a copy of this licence, visit http://creativecommons.org/licenses/by/4.0/.

\section{References}

Aal, K., Di Pietro, L., Edvardsson, B., Renzi, M. F., \& Guglielmetti Mugion, R. (2016). Innovation in service ecosystems: An empirical study of the integration of values, brands, service systems and experience rooms. Journal of Service Management, 27(4), 619-651.

Antons, D., \& Breidbach, C. F. (2018). Big data, big insights? Advancing service innovation and design with machine learning. Journal of Service Research, 21(1), 17-39.

Backaler, J. (2018). Digital influence: Unleash the power of influencer marketing to accelerate your global business. Information, Communication \& Society, 22(10), 1528-1530.

Baron, S., Patterson, A., Maull, R., \& Warnaby, G. (2017). Feed people first: A service ecosystem perspective on innovative food waste reduction. Journal of Service Research, 21(1), 135-150.

Barrett, M., Davidson, E., Prabhu, J., \& Vargo, S. L. (2015). Service innovation in the digital age: Key contributions and future directions. MIS Quarterly, 39(1), 135-154.

Brodie, R. J., Hollebeek, L. D., Jurić, B., \& Ilić, A. (2011). Customer engagement: Conceptual domain, fundamental propositions, and implications for research. Journal of Service Research, 14(3), 252-271.

Brown, G., \& Michinov, N. (2019). Measuring latent ties on facebook: A novel approach to studying their prevalence and relationship with bridging social capital. Technology in Society, 59, 101-176.

Busser, J. A., Shulga, L. V., \& Kang, H. J. (Annette). (2019). Customer disposition to social exchange in co-innovation. International Journal of Hospitality Management, 76(Part A), 299-307.

Cabiddu, F., De Carlo, M., \& Piccoli, G. (2014). Social media affordances: Enabling customer engagement. Annals of Tourism Research, 48, 175-192.

Carlborg, P., Kindström, D., \& Kowalkowski, C. (2014). The evolution of service innovation research: A critical review and synthesis. Service Industries Journal, 34(5), 373-398.

Chan, C., \& Holosko, M. J. (2017). The utilization of social media for youth outreach engagement: A case study. Qualitative Social Work, 16(5), 680-697.

Chen, Z. Y., Fan, Z. P., \& Sun, M. (2019). Individual-level social influence identification in social media: A learning-simulation coordinated method. European Journal of Operational Research, 273(3), 1005-1015.

Dahl, D. W., Fuchs, C., \& Schreier, M. (2015). Why and when consumers prefer products of user-driven firms: A social identification account. Management Science, 61(8), 1978-1988.

Daniel, E. S., Crawford Jackson, E. C., \& Westerman, D. K. (2018). The influence of social media influencers: Understanding online vaping communities and parasocial interaction through the lens of taylor's six-segment strategy wheel. Journal of Interactive Advertising, 18(2), 96-109.

Davis, A., Khazanchi, D., Murphy, J., Zigurs, I., \& Owens, D. (2009). Avatars, people, and virtual worlds: Foundations for research in metaverses. Journal of the Association for Information Systems, 10(2), 90-117.

De Veirman, M., Cauberghe, V., \& Hudders, L. (2017). Marketing through instagram influencers: The impact of number of followers and product divergence on brand attitude. International Journal of Advertising, 36(5), 798-828.

Djafarova, E., \& Rushworth, C. (2017). Exploring the credibility of online celebrities' Instagram profiles in influencing the purchase decisions of young female users. Computers in Human Behavior, 68, 1-7.

Edvardsson, B., Kristensson, P., Magnusson, P., \& Sundström, E. (2012). Customer integration within service development - A review of methods and an analysis of insitu and exsitu contributions. Technovation, 32(7-8), 419-429.

Eisenhardt, K. M. (1989). Building theories from case study research. Academy of Management Review, 14(4), 532-550.

Erz, A., \& Christensen, A. B. H. (2018). Transforming consumers into brands: Tracing transformation processes of the practice of blogging. Journal of Interactive Marketing, 43, 69-82.

Evans, N. J., Phua, J., Lim, J., \& Jun, H. (2017). Disclosing instagram influencer advertising: The effects of disclosure language on advertising recognition, attitudes, and behavioral intent. Journal of Interactive Advertising, 17(2), 138-149.

Fang, E., Palmatier, R. W., \& Grewal, R. (2011). Effects of customer and innovation asset configuration strategies on firm performance. Journal of Marketing Research, 48(3), 587-602.

Faraj, S., Jarvenpaa, S. L., \& Majchrzak, A. (2011). Knowledge collaboration in online communities. Organization Science, 22(5), $1224-1239$.

Fontana A., \& Frey J. H. (2000). The interview: From structured questions to negotiated text. In N. K. Denzin \& Y. S. Lincoln (Eds.), Handbook of qualitative research (2nd ed., pp. 645-672). Sage Publications.

Friend, S. B., \& Malshe, A. (2016). Key skills for crafting customer solutions within an ecosystem: A theories-in-use perspective. Journal of Service Research, 19(2), 174-191. 
Gibbs, J. L., Rozaidi, N. A., \& Eisenberg, J. (2013). Overcoming the "ideology of openness": Probing the affordances of social media for organizational knowledge sharing. Journal of Computer-Mediated Communication, 19(1), 102-120.

Graebner, M. E., \& Eisenhardt, K. M. (2013). The seller's side of the as story : Acquisition and courtship as governance in syndicate firms entrepreneurial. Administrative Science Quarterly, 49(3), 366-403.

Grönroos, C. (2012). Conceptualising value co-creation: A journey to the 1970s and back to the future. Journal of Marketing Management, 28(13-14), 1520-1534.

Gustafsson, A., Snyder, H., \& Witell, L. (2020). Service innovation: A new conceptualization and path forward. Journal of Service Research, 23(2), 111-115.

Harmeling, C. M., Moffett, J. W., Arnold, M. J., \& Carlson, B. D. (2017). Toward a theory of customer engagement marketing. Journal of the Academy of Marketing Science, 45(3), 312-335.

Hibbert, S., Winklhofer, H., \& Temerak, M. S. (2012). Customers as resource integrators: Toward a model of customer learning. Journal of Service Research, 15(3), 247-261.

Hollebeek, L. D., Srivastava, R. K., \& Chen, T. (2019). S-D logicinformed customer engagement: Integrative framework, revised fundamental propositions, and application to CRM. Journal of the Academy of Marketing Science, 47(1), 161-185.

Hughes, C., Swaminathan, V., \& Brooks, G. (2019). Driving brand engagement through online social influencers: An empirical investigation of sponsored blogging campaigns. Journal of Marketing, 83(5), 78-96.

Hughes, T., Vafeas, M., \& Hilton, T. (2018). Resource integration for co-creation between marketing agencies and clients. European Journal of Marketing, 52(5-6), 1329-1354.

Jing, X., \& Xie, J. (2011). Group buying: A new mechanism for selling through social interactions. Management Science, 57(8), 1354-1372.

Johnson, J. S., \& Sohi, R. S. (2016). Understanding and resolving major contractual breaches in buyer-seller relationships: A grounded theory approach. Journal of the Academy of Marketing Science, 44(2), 185-205.

Kaplan, A. M., \& Haenlein, M. (2010). Users of the world, unite! The challenges and opportunities of social media. Business Horizons, 53(1), 59-68.

Karahanna, E., Xu, S. X., Xu, Y., \& Zhang, N. (2018). The needsaffordances-features perspective for the use of social media. MIS Quarterly, 42(3), 737-756.

Knoll, J., Schramm, H., Schallhorn, C., \& Wynistorf, S. (2015). Good guy vs. bad guy: The influence of parasocial interactions with media characters on brand placement effects. International Journal of Advertising, 34(5), 720-743.

Kristensson, P., Gustafsson, A., \& Archer, T. (2004). Harnessing the creative potential among users. Journal of Product Innovation Management, 21(1), 4-14.

Lanz, A., Goldenberg, J., Shapira, D., \& Stahl, F. (2019). Climb or jump: Status-based seeding in user-generated content networks. Journal of Marketing Research, 56(3), 361-378.

Lee, S. K., Kramer, M. W., \& Guo, Y. (2019). Social media affordances in entry-level employees' socialization: Employee agency in the management of their professional impressions and vulnerability during early stages of socialization. New Technology, Work and Employment, 34(3), 244-261.

Leidner, D. E., Gonzalez, E., \& Koch, H. (2018). An affordance perspective of enterprise social media and organizational socialization. Journal of Strategic Information Systems, 27(2), $117-138$

Leonardi, P. M. (2013). When does technology use enable network change in organizations? A comparative study of feature use and shared affordances. MIS Quartely, 37(3), 749-775.
Li, F. F., Larimo, J., \& Leonidou, L. C. (2021). Social media marketing strategy: Definition, conceptualization, taxonomy, validation, and future agenda. Journal of the Academy of Marketing Science, 49(1), 51-70.

Liang, T. P., \& Turban, E. (2011). Introduction to the special issue social commerce: A research framework for social commerce. International Journal of Electronic Commerce, 16(2), 5-14.

Lou, C., Tan, S. S., \& Chen, X. (2019). Investigating consumer engagement with influencer- vs. brand-promoted ads: The roles of source and disclosure. Journal of Interactive Advertising, 19(3), 169-186.

Lusch, R. F., Vargo, S. L., \& O’Brien, M. (2007). Competing through service: Insights from service-dominant logic. Journal of Retailing, 83(1), 5-18.

Lusch, R. F., \& Nambisan, S. (2015). Service innovation: A servicedominant logic perspective. MIS Quarterly, 39(1), 155-175.

Magnusson, P. R., Matthing, J., \& Kristensson, P. (2003). Managing user involvement in service innovation: Experiments with innovating end users. Journal of Service Research, 6(2), 111-124.

Majchrzak, A., \& Markus, M. L. (2012). Technology affordances and constraints in management information systems. Encyclopedia of Management Theory (Ed: E. Kessler), Sage Publications, Forthcoming.

Majchrzak, A., Faraj, S., Kane, G. C., \& Azad, B. (2013). The contradictory influence of social media affordances on online communal knowledge sharing. Journal of Computer-Mediated Communication, 19(1), 38-55.

Markus, M. L., \& Silver, M. S. (2008). A foundation for the study of IT effects: A new look at DeSanctis and Poole's concepts of structural features and spirit. Journal of the Association for Information Systems, 9(10), 609-632.

McAfee, A. (2009). Enterprise 2.0: New collaborative tools for your organization's toughest challenges. Harvard Business School Press Books.

Nambisan, S., Lyytinen, K., Majchrzak, A., \& Song, M. (2017). Digital innovation management: Reinventing innovation management research in a digital world. MIS Quartely, 41(1), 223-238.

Ng, S. C., Plewa, C., \& Sweeney, J. C. (2016). Professional service providers' resource integration styles (PRO-RIS): Facilitating customer experiences. Journal of Service Research, 19(4), 380-395.

Ostrom, A. L., Parasuraman, A., Bowen, D., Patrício, L., \& Voss, C. A. (2015). Service research priorities in a rapidly changing context. Journal of Service Research, 18(2), 127-159.

Patrício, L., Gustafsson, A., \& Fisk, R. (2018). Upframing service design and innovation for research impact. Journal of Service Research, 21(1), 3-16.

Pee, L. G. (2018). Affordances for sharing domain-specific and complex knowledge on enterprise social media. International Journal of Information Management, 43, 25-37.

Petri, J., \& Jacob, F. (2016). The customer as enabler of value (co)creation in the solution business. Industrial Marketing Management, 56, 63-72.

Raja-Yusof, R. J., Norman, A. A., Abdul-Rahman, S. S., Nazri, N., \& Mohd-Yusoff, Z. (2016). Cyber-volunteering: Social media affordances in fulfilling NGO social missions. Computers in Human Behavior, 57, 388-397.

Goldenberg, J., Han, S., Lehmann, D. R., \& Weon Hong, J. (2009). The Role of Hubs in the Adoption Process. Journal of Marketing, 73(2), 1-13.

Schouten, A. P., Janssen, L., \& Verspaget, M. (2020). Celebrity vs. Influencer endorsements in advertising: the role of identification, credibility, and Product-Endorser fit. International Journal of Advertising, 39(2), 258-281.

Shah, S., \& Tripsas, M. (2007). The accidental entrepreneur: The emergent and collective process of user entrepreneurship. Strategic Entrepreneurship Journal, 1(1-2), 123-140. 
Shan, Y., Chen, K. J., \& Lin, J. S. (2019). When social media influencers endorse brands: The effects of self-influencer congruence, parasocial identification, and perceived endorser motive. International Journal of Advertising, 39(5), 590-610.

Shao, Z., \& Pan, Z. (2019). Building Guanxi network in the mobile social platform: A social capital perspective. International Journal of Information Management, 44, 109-120.

Shwartz-Asher, D., Chun, S., Adam, N. R., \& Snider, K. L. (2020). Knowledge sharing behaviors in social media. Technology in Society, 63, 101426.

Silverman, D., \& Marvasti, A. (2008). Doing qualitative research: A comprehensive guide. Sage Publications.

Skålén, P., Gummerus, J., von Koskull, C., \& Magnusson, P. R. (2015). Exploring value propositions and service innovation: A servicedominant logic study. Journal of the Academy of Marketing Science, 43(2), 137-158.

Song, Q., Wang, Y., Chen, Y., Benitez, J., \& Hu, J. (2019). Impact of the usage of social media in the workplace on team and employee performance. Information and Management, 56(8), 103-160.

Stephen, A. T., \& Toubia, O. (2010). Deriving value from social commerce networks. Journal of Marketing Research, 47(2), 215-228.

Strauss, A. L., \& Corbin, J. M. (1998). Basics of Qualitative Research: Techniques and Procedures for Developing Grounded Theory. Sage(Vol. 2nd).

Sudbury-Riley, L., Hunter-Jones, P., Al-Abdin, A., Lewin, D., \& Naraine, M. V. (2020). The trajectory touchpoint technique: A deep dive methodology for service innovation. Journal of Service Research, 23(2), 229-251.

Suddaby, R. (2006). From the editors: What grounded theory is not. Academy of Management Journal, 49(4), 633-642.

Tim, Y., Pan, S. L., Bahri, S., \& Fauzi, A. (2017). Digitally enabled affordances for community-driven environmental movement in rural Malaysia. Information Systems Journal, 1-28.

Treem, J. W., \& Leonardi, P. M. (2013). Social media use in organizations: exploring the affordances of visibility, editability, persistence, and association. Annals of the International Communication Association, 36(1), 143-189.
Vaast, E., \& Kaganer, E. (2013). Social media affordances and governance in the workplace: An examination of organizational policies. Journal of Computer-Mediated Communication, 19(1), 78-101.

Vargo, S. L., \& Lusch, R. F. (2004). Evolving to a new dominant logic for marketing. Journal of Marketing, 68(1), 1-17.

Vargo, S. L., \& Lusch, R. F. (2008). Service-dominant logic: Continuing the evolution. Journal of the Academy of Marketing Science, $36(1), 1-10$.

Vargo, S. L., \& Lusch, R. F. (2016). Institutions and axioms: An extension and update of service- dominant logic. Journal of the Academy of Marketing Science, 44(1), 5-23.

Vargo, S. L., Wieland, H., \& Akaka, M. A. (2015). Innovation through institutionalization: A service ecosystems perspective. Industrial Marketing Management, 44, 63-72.

Volkoff, O., \& Strong, D. M. (2013). Critical realism and affordances: Theorizing IT-associated organizational change processes. MIS Quarterly, 37(3), 819-834.

von Hippel, E. (1986). Lead users: A source of novel product concepts. Management Science, 32(7), 791-805.

von Hippel, E. (2005). Democratizing innovation: The evolving phenomenon of user innovation. Journal Fur Betriebswirtschaft, 55(1), 63-78.

Wang, H. S., Noble, C. H., Dahl, D. W., \& Park, S. (2019). Successfully communicating a cocreated innovation. Journal of Marketing, 83(4), 38-57.

Witell, L., Snyder, H., Gustafsson, A., Fombelle, P., \& Kristensson, P. (2016). Defining service innovation: A review and synthesis. Journal of Business Research, 69(8), 2863-2872.

Yi, Y., \& Gong, T. (2013). Customer value co-creation behavior: Scale development and validation. Journal of Business Research, 66(9), $1279-1284$.

Yin, R. K. (2009). Case study research : design and methods. Sage.

Publisher's note Springer Nature remains neutral with regard to jurisdictional claims in published maps and institutional affiliations. 